Journal of Applied Pharmaceutical Science Vol. 6 (05), pp. 007-017, May, 2016

Available online at http://www.japsonline.com

DOI: $10.7324 / \mathrm{JAPS} .2016 .60502$

ISSN 2231-3354 (cc) BY-NC-SA

\title{
Synthesis and antibacterial activity of novel 2-(arylimino)thiazolidin- 4-one and 2-(benzylidenehydrazono)-3-arylthiazolidin-4-one derivatives
}

\author{
Ebaa M. El-Hossary ${ }^{1,2, *}$, Yassin M. Nissan ${ }^{3}$, Katharina Edkins ${ }^{4}$, Heike Bruhn ${ }^{5}$ \\ ${ }^{1}$ Institute of Pharmacy \& Food Chemistry, University of Würzburg, Am Hubland, 97074 Würzburg, Germany. ${ }^{2}$ Permanent address: National Centre for \\ Radiation Research \& Technology, Egyptian Atomic Energy Authority, Ahmed El-Zomor St. 3, El-Zohoor Dist., Cairo, Egypt. ${ }^{3}$ Department of \\ Pharmaceutical Chemistry, Faculty of Pharmacy, Cairo University, Cairo 11562, Egypt. ${ }^{4}$ School of Medicine, Pharmacy and Health, Durham University, \\ Stockton-on-Tees, United Kingdom. ${ }^{5}$ Institute for Molecular Infection Biology, SFB 630, Würzburg University, Josef-Schneider-Str. 2, Bau 15, 97080 \\ Würzburg, Germany.
}

\begin{tabular}{l} 
ARTICLE INFO \\
\hline Article history: \\
Received on: $31 / 12 / 2015$ \\
Revised on: 09/03/2016 \\
Accepted on: 08/04/2016 \\
Available online: $28 / 05 / 2016$ \\
\hline Key words: \\
1,3-Thiazolidin-4-one \\
Antibacterial activity \\
Minimum inhibitory \\
concentration Minimum \\
bactericidal concentration \\
Biofilm formation.
\end{tabular}

\section{INTRODUCTION}

Currently, infectious diseases are the second leading cause of death worldwide. Bacterial resistance against antibiotics is an increasing health problem in both community and hospital setting. It has a note worthy impact on the mortality rates, morbidity rates and the financial burden associated. Although various novel antibacterial drugs had been introduced into the market in the past decades, the prevalence of multidrug-resistant

\footnotetext{
* Corresponding Author

Ebaa Mostafa El-Hossary, Institute of Pharmacy \& Food Chemistry, University of Würzburg, Am Hubland, 97074 Würzburg, Germany.

${ }^{2}$ Permanent address: National Centre for Radiation Research \& Technology, Egyptian Atomic Energy Authority, Ahmed El-Zomor St. 3, El-Zohoor Dist., Cairo, Egypt. Email: ebaa.elhossary@eaea.org.eg
}

pathogens remains among the major health problems which raises severe concern around the globe(Bassetti et al., 2013; Butler et al., 2013; Kumarasamy et al., 2010; Lewis, 2013; Pendleton et al., 2013). Staphylococci and Enterococci are Gram-positive bacteria that are responsible for several community and hospital acquired infections. Staphylococcus aureus causes a wide range of infections from simple skin and soft tissue infections to serious illnesses like pneumonia, infective endocarditis and sepsis (Tong et al., 2015; Valour et al., 2013).

Staphylococcus epidermidis is regarded as the most frequent cause of nosocomial and indwelling medical deviceassociated infections. It causes more persistent infections due to its high ability to resist antibiotic treatments through biofilm formation (Gomes et al., 2014; Namvar et al., 2014; Otto, 2009). 
Since the beginning of the antibiotic era, the isolation of multidrug resistant enterococci has become increasingly common in hospital setting. Enterococcus faecalis and Enterococcus faecium are the most predominant species, cultured from humans, representing more than $90 \%$ of clinical isolates. E. faecalis infective endocarditis is still a very serious disease, associated with the presence of highly gentamicin-resistant strains and in-hospital mortality rates around 20\% (Courvalin, 2006; Dahl and Bruun, 2013; de Perio et al., 2006; Deshpande et al., 2007). On the other hand, the gram-negative bacterium Yersinia pestis is the causative agent of pneumonic plague; which is the most severe manifestation of plague. The mortality rates of pneumonic plague are approximately $100 \%$ in untreated cases (Pechous et al., 2015).

1,3-Thiazolidin-4-ones are a class of compounds that have shown potential as antibacterials (Aridoss et al., 2009; Gopalakrishnan et al., 2009; Jain et al., 2012; Poyraz et al., 2013; Sayyed et al., 2006; Verma and Saraf, 2008; Vicini et al., 2006; Vicini et al., 2008). Thiazolidin-4-ones have been found as inhibitors of the bacterial enzyme MurB; a key enzyme responsible for the synthesis of peptidoglycan (Andres et al., 2000). In this study, a series of 2-(arylimino)thiazolidin-4-ones and 2-(benzylidenehydrazono)-3-arylthiazolidin-4-ones was synthesized. The synthesized compounds were tested for their in vitro antibacterial activity against selected clinically important pathogenic microbes.

\section{RESULTS AND DISCUSSION}

\section{Chemistry}

The synthesis of the target 1,3-thiazolidin-4-one derivatives started with the conversion of the commercially available sulfanilamide $\mathbf{1}$ into the corresponding thioureido derivatives 2a-c (Roth and Degering, 1945) when sulfanilamide 1reactedwith the appropriate isothiocyanate derivative (Scheme 1).The thioureido derivatives 2a-c were then refluxed with an equimolar amount of chloroacetic acid in glacial acid to give the respective 4-(4-oxo-3-substitutedthiazolidin-2-ylideneamino) benzenesulfonamide derivatives 3a-c (Scheme 1).IR spectra of compounds 3a-c revealed strong characteristic intense bands at $1712-1724 \mathrm{~cm}^{-1}$ which correspond to the carbonyl group of the 1,3-thiazolidin-4-one ring. ${ }^{1} \mathrm{H}$-NMR spectra of compounds 3a-c displayed singlets at 4.04-4.16 ppm for the two protons of the methylene (- $\left.\mathrm{CH}_{2}-\right)$ of the 1,3-thiazolidin-4-one nucleus. ${ }^{13} \mathrm{C}-\mathrm{NMR}$ spectra of compounds 3a-c exhibited new signals at 29.07-32.74 ppm, ascribed to the methylene group, confirming the intramolecular cyclization and formation of the 1,3-thiazolidin-4one ring. Similarly, compounds 4a-c were synthesized by refluxing the thioureido derivatives 2a-c with an equimolar amount of diethyl bromomalonate in glacial acid (Scheme 1). IR spectra of the compounds $\mathbf{4 a - c}$ were characterized by the presence of two strong bands corresponding to the carbonyl group of the ethylester moiety and the carbonyl group of the 1.3-thiazolidin-4one ring at $1689-1751 \mathrm{~cm}^{-1} .{ }^{1} \mathrm{H}-\mathrm{NMR}$ spectra of compounds 4a-c exhibited triplets and quartets corresponding to the ethylester substituent at position 5. The synthesis of compounds 5a-c was attained by refluxing the corresponding thioureido derivatives $\mathbf{2 a - c}$ with an equimolar amount of maleic anhydride in glacial acid (Scheme 1). IR spectra of the 2-(4-oxothiazolidin-5-yl)acetic acid derivatives 5a-c showed two bands representing the carbonyl group of the 1,3-thiazolidin-4-one nucleus and the carbonyl group of the acetic acid moiety at $1660-1708 \mathrm{~cm}^{-1}$.

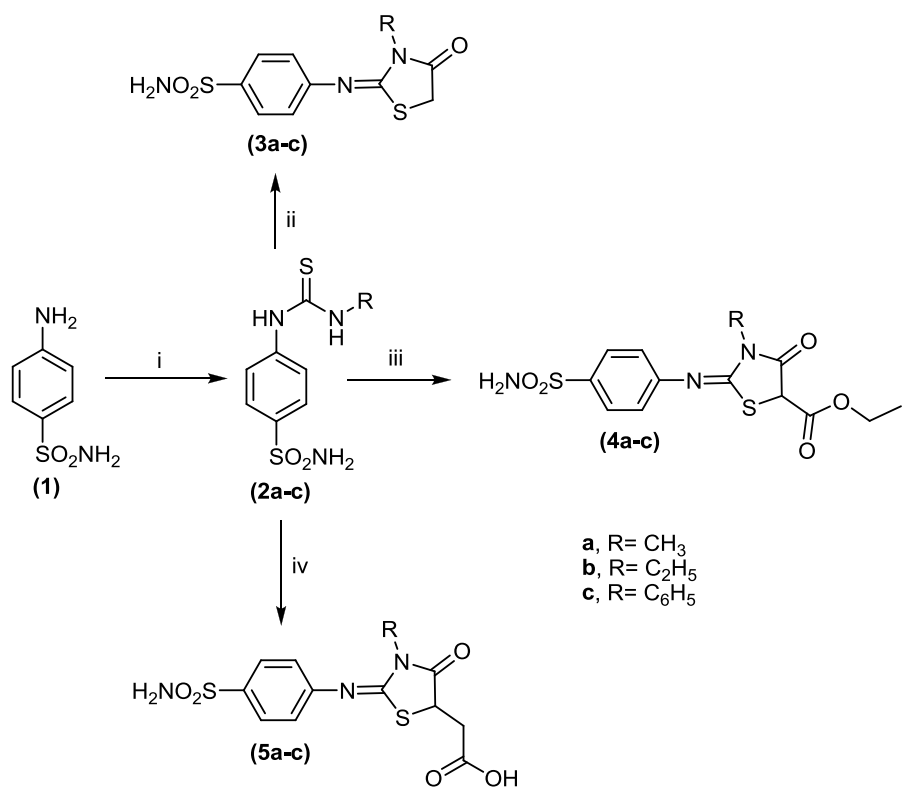

Scheme. 1: Synthesis of compounds 3a-c, 4 a-c and 5 a-c.

Reagents and conditions: (i) R-NCS / EtOH / TEA / reflux 24 h. (ii) $\mathrm{ClCH}_{2} \mathrm{COOH} / \mathrm{AcOH} /$ anhydrous $\mathrm{CH}_{3} \mathrm{COONa} /$ reflux $24 \mathrm{hr}$. (iii) Diethylbromomalonate / $\mathrm{AcOH} /$ anhydrous $\mathrm{CH}_{3} \mathrm{COONa} /$ reflux 24 h. (iv) Maleic anhydride / AcOH / reflux $24 \mathrm{~h}$.

The 4-isothiocyanatobenzenesulfonamide $\mathbf{6}$ was obtained by stirring a solution of sulfanilamide $\mathbf{1}$ in distilled water containing an equimolar amount of thiophosgen (El-Gaby et al., 2009). Compound 6 was then stirred with an excess amount of hydrazine hydrate to give $N$-(4-sulfamoylphenyl)hydrazinecarbothioamide 7 (Sriram et al., 2009). The Schiff's bases 8a,b were prepared by refluxing compound7 with an equimolar amount of the appropriate aldehyde in methanol (Scheme 2). ${ }^{1} \mathrm{H}-\mathrm{NMR}$ spectrum of compound $\mathbf{8 a}$ displayed signals at 10.32 and $12.05 \mathrm{ppm}$, which were exchangeable in $\mathrm{D}_{2} \mathrm{O}$, confirming the presence of two $\mathrm{NH}$ groups of the hydrazinecarbothioamide. The ${ }^{13} \mathrm{C}-\mathrm{NMR}$ spectrum of compound 8b was characterized by the appearance of a new signal at 39.66 ppm ascribed to the two carbon atoms of the $\mathrm{N}\left(\mathrm{CH}_{3}\right)_{2}$ group.

Additionally, ${ }^{1} \mathrm{H}-\mathrm{NMR}$ spectra of compounds 8a,b exhibited signals at 8.15 and $8.06 \mathrm{ppm}$, respectively, for the imine proton of $(\mathrm{N}=\mathrm{CH})$. In a similar way to the synthetic pathway of the target 1,3-thiazolidin-4-ones outlined in Scheme 1, the 2-(4(substituted)benzylidene)- $N$-(4-sulfamoylphenyl)-hydrazinecarbo thioamides 8a,b were cyclized into the corresponding 1,3thiazolidin-4-one derivatives $\mathbf{9 a}, \mathbf{b}$ by reaction with an equimolar amount of monochloroacetic acid (Scheme 2). 

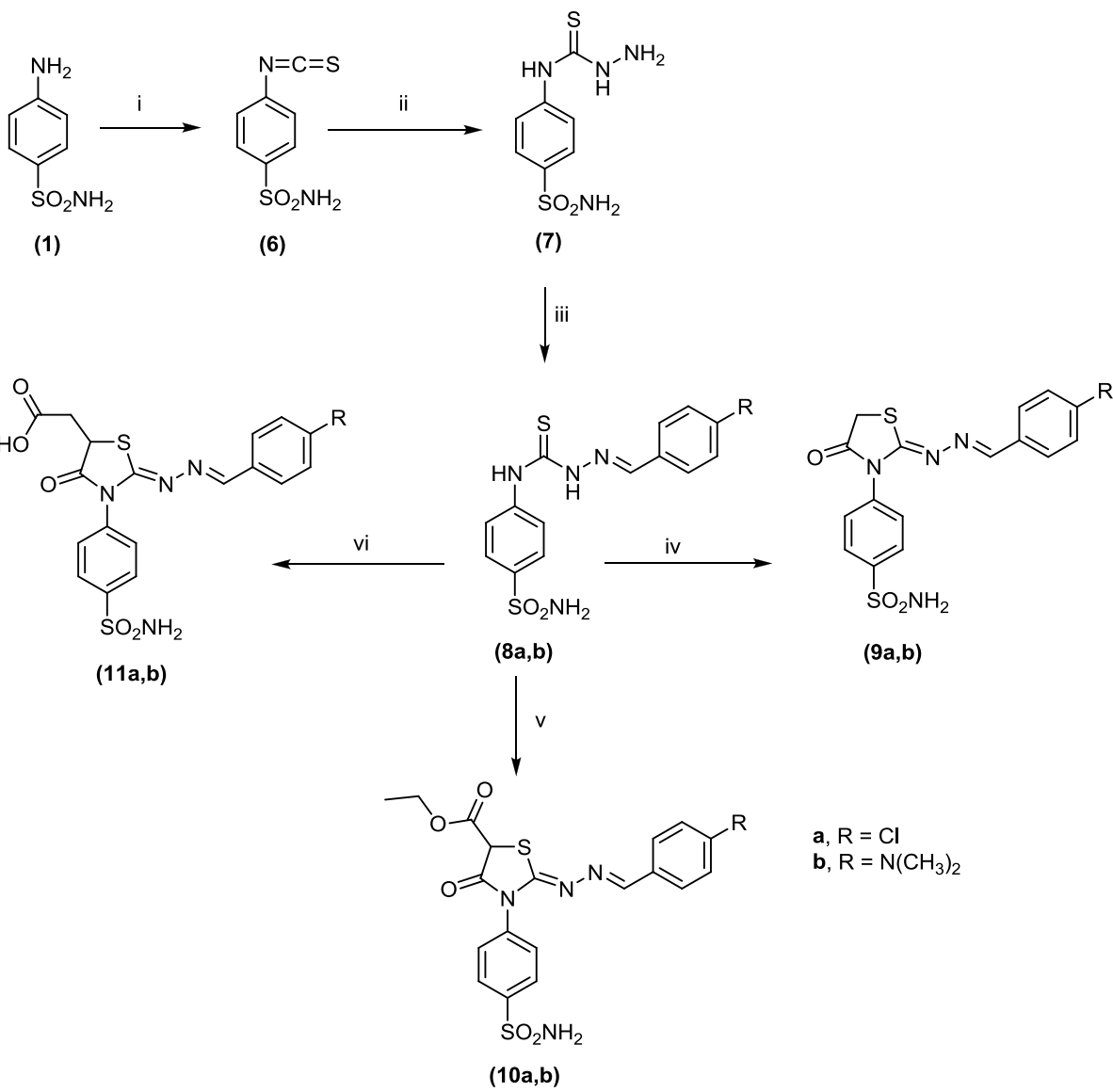

Scheme. 2: Synthesis of compounds $9 \mathbf{a}, \mathbf{b}, \mathbf{1 0 a}, \mathbf{b}$ and $\mathbf{1 1 a}, \mathbf{b}$.

Reagents and conditions: (i) $\mathrm{CSCl}_{2} / \mathrm{H}_{2} \mathrm{O} / \mathrm{HCl} /$ stirring RT / 2 h. (ii) $\mathrm{NH}_{2} \mathrm{NH}_{2} \cdot \mathrm{H}_{2} \mathrm{O} /$ isopropanol / stirring RT / 2 h. (iii) Ar- $\mathrm{CHO} / \mathrm{MeOH} / \mathrm{reflux} 5$ h. (iv) $\mathrm{ClCH}_{2} \mathrm{COOH} / \mathrm{AcOH} /$ anhydrous $\mathrm{CH}_{3} \mathrm{COONa} /$ reflux $24 \mathrm{hr}$. (v) Diethylbromomalonate / $\mathrm{AcOH} /$ anhydrous $\mathrm{CH}_{3} \mathrm{COONa} /$ reflux $24 \mathrm{~h}$. (vi) Maleic anhydride / $\mathrm{AcOH} /$ reflux $24 \mathrm{~h}$.

IR spectra of compounds 9a,b revealed characteristic bands at $1732,1697 \mathrm{~cm}^{-1}$, respectively, which correspond to the carbonyl group of the 1,3-thiazolidin-4-one ring. ${ }^{1} \mathrm{H}-\mathrm{NMR}$ spectra of compounds 9a,b displayed signals at 4.13 and $4.09 \mathrm{ppm}$, respectively, for the two protons of the methylene group of the 1,3-thiazolidin-4-one ring. In addition, ${ }^{1} \mathrm{H}-\mathrm{NMR}$ spectrum of compound $9 \mathrm{~b}$ revealed a singlet at $2.97 \mathrm{ppm}$ representing the 6 protons of the dimethylamino group. The Schiff's bases 8a,b were also cyclized into the corresponding 1,3-thiazolidin-4-one derivatives 10a,b, by refluxing with an equimolar amount of diethyl bromomalonate in glacial acetic acid (Scheme 2). IR spectra of compounds 10a,b showed two bands for the two carbonyl groups; the ethyl ester moiety and the 1,3-thiazolidin-4one ring at 1612-1739 $\mathrm{cm}^{-1} .{ }^{1} \mathrm{H}-\mathrm{NMR}$ spectra of compounds 10a,b exhibited triplets and quartets representing the ethyl group of the ethyl ester substituent at position 5. Finally, the synthesis of the 1,3-thaizolidin-4-one derivatives 11a,b was attained by refluxing the corresponding Schiff's bases 8a,b, with an equimolar amount of maleic anhydride in glacial acetic acid (Scheme 2). ${ }^{1} \mathrm{H}-\mathrm{NMR}$ spectra of compounds 11a,b revealed new signals at 10.86 and $10.75 \mathrm{ppm}$, respectively, corresponding to the one proton of the carboxylic $\mathrm{OH}$ group. To confirm the cyclization pattern of the 1,3-thiazolidin-4-onering, compound $\mathbf{3 a}$ was subjected to $\mathrm{x}$-ray crystallography measurement. Crystals suitable for X-ray diffraction were grown from dichloromethane solution by slow cooling. The structure could be determined in the triclinic space group P-1 with four symmetric independent molecules in the asymmetric unit $\left(Z^{\prime}=4\right)$. This is due to a break in symmetry by the disorder of the central phenyl rings. The bond lengths and angles are all within normal ranges (Allen et al., 1987). The molecules of 3a adopted two different conformations in this structure, with the angle between the thiazolidinone and the phenyl ring either $60^{\circ}$ or $-50^{\circ}$ (Figure 1a). This has no influence on the overall packing and it is assumed that due to the comparable size of the phenyl ring and the sulfonamide terminal group, the phenyl ring can rotate rather freely. The crystal packing consists of pseudo-centrosymmetric dimers of 3a stabilized through weak C$\mathrm{H} \cdots \mathrm{O}$ hydrogen bonds (Figure 1b). These dimmers are connected to the next dimer through $\mathrm{N}-\mathrm{H} \cdots \mathrm{O}$ hydrogen bonds, between the terminal amide group and the $\mathrm{C}=\mathrm{O}$ group of the thiazolidinone rings, linking the structure together along the crystallographic $b$ axis. An additional $\mathrm{N}-\mathrm{H} \cdots \mathrm{O}$ hydrogen bond between the terminal amide group and the $\mathrm{S}=\mathrm{O}$ group of the sulfonamide links the molecules along $b$. This packing results in the formation of stacks along the crystallographic $a$-axis which consist of alternate disordered and non-disordered molecules. 


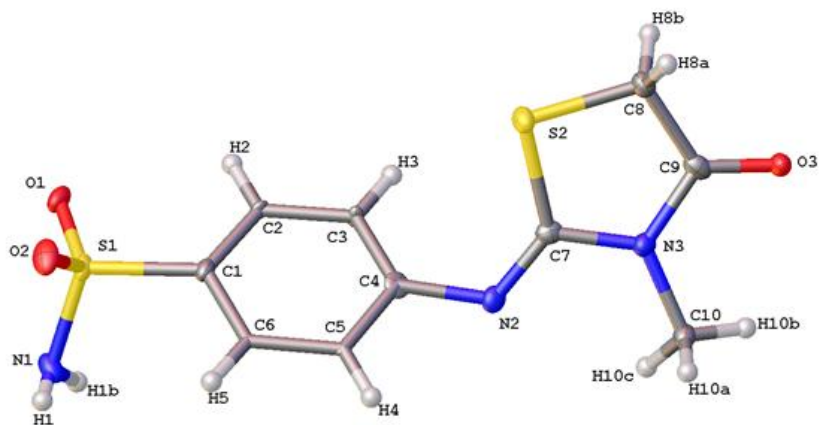

(a)

Single molecule and naming scheme.

g. 1: Molecular structure of compound 3a as determined by X-ray single crystal diffraction: a) molecule and naming scheme and b) assymetric unit with hydrogen bonds. Element (colour): Carbon (grey), oxygen (red), nitrogen (blue), sulfur (yellow), hydrogen (light grey). Atomic displacement parameters are drawn at $50 \%$ probability.

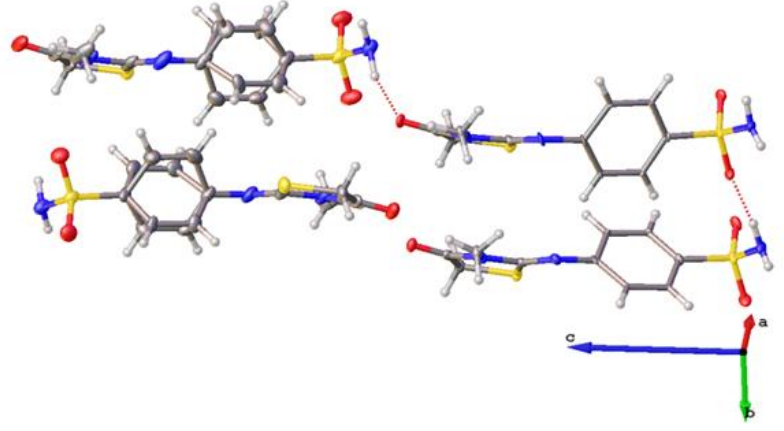

(b) Asymmetric unit with indication of hydrogen.<smiles>[R]N1C(=O)C(C(=O)OCC)SC1=Nc1ccc(S(N)(=O)=O)cc1</smiles>

Table 1: Antibacterial activity of the tested compounds 4a and 4c.

\begin{tabular}{|c|c|c|c|c|c|c|c|}
\hline & \multirow[b]{2}{*}{ Tested bacterial strain } & \multicolumn{2}{|c|}{ Compound 4a } & \multicolumn{2}{|c|}{ Compound $\mathbf{4 c}$} & \multirow{2}{*}{$\begin{array}{c}\text { Gentamycin } \\
\mathrm{MIC} \\
(\mu \mathrm{M})\end{array}$} & \multirow{2}{*}{$\begin{array}{c}\text { Tetracycline } \\
\text { MIC } \\
(\mu \mathrm{M})\end{array}$} \\
\hline & & $\begin{array}{l}\mathrm{MIC}^{*} \\
(\mu \mathrm{M})\end{array}$ & $\begin{array}{c}\mathrm{MBC}^{* * *} \\
(\mu \mathrm{M})\end{array}$ & $\begin{array}{l}\text { MIC } \\
(\mu \mathrm{M})\end{array}$ & $\begin{array}{l}\text { MBC } \\
(\mu \mathrm{M})\end{array}$ & & \\
\hline \multirow{10}{*}{ Gram-positive } & S. aureus 8325 & 10 & $>40$ & 5 & $>40$ & 0.21 & NT*** \\
\hline & S. aureus HG001 & 10 & $>40$ & 5 & $>40$ & NT & NT \\
\hline & S. aureus MA12 & 10 & $>40$ & 5 & $>40$ & NT & NT \\
\hline & S. aureus RN1 & 40 & $>40$ & 20 & $>40$ & NT & NT \\
\hline & S. aureus Xen29 & 10 & $>40$ & 5 & $>40$ & NT & NT \\
\hline & S. epidermidis RP62A & 5 & $>40$ & 5 & $>40$ & NT & 0.83 \\
\hline & S. epidermidis 195 & 10 & $>40$ & 10 & $>40$ & NT & NT \\
\hline & S. epidermidis 047 & 5 & $>40$ & 2.5 & $>40$ & NT & NT \\
\hline & E. faecalis $\mathrm{JH} 212$ & 5 & 10 & 2.5 & 5 & 26.2 & NT \\
\hline & E. faecium 6413 & $>40$ & $>40$ & $>40$ & $>40$ & NT & 0.83 \\
\hline \multirow{4}{*}{ Gram-negative } & E. coli 536 & $>40$ & $>40$ & $>40$ & $>40$ & 0.83 & NT \\
\hline & P. aeruginosa & $>40$ & $>40$ & $>40$ & $>40$ & 3.4 & NT \\
\hline & Y.pestis KUMA & 10 & $>40$ & 5 & $>40$ & 1.7 & NT \\
\hline & Y. pseudotuberculosis $25201 \mathrm{~A}$ & $>40$ & $>40$ & $>40$ & $>40$ & 1.7 & NT \\
\hline
\end{tabular}

* MIC: Minimal Inhibitory Concentration. ** MBC: Minimal Bactericidal Concentration. *** NT: Not tested.

\section{Antibacterial activity}

All of the newly synthesized final compounds have been screened at a highest concentration of $40 \mu \mathrm{M}$, for their in vitro antibacterial activity against selected clinically important pathogenic bacteria. These bacteria include the Gram-positive bacteria; S. aureus (Strains; 8325, HG001, MA12, RN1 and Xen29), S. epidermidis (Strains; RP62A, 195 and 047), E.faecalisJH212, E. faecium6413 and the Gram-negative bacteria; Escherichia coli 536, Pseudomonas aeruginosa, Y. pestis KUMA and Yersinia pseudotuberculosis 252 01A. Staphylococci, Enterococci and P. aeruginosa belong to the so called "ESKAPE" pathogens; pathogenic bacteria that are responsible for the highest impact in bacterial resistance (Pendleton et al., 2013).
Moreover, $S$. aureus, $S$. epidermidis, $P$. aeruginosa, and E. coli can cause persistent infections that are resistant to antibiotic treatments due to their ability to form biofilm (Romling and Balsalobre, 2012).

All the tested compounds have been evaluated for their in vitro antibacterial activity by measuring the minimum inhibitory concentration (MIC) and the minimum bactericidal concentration (MBC). MIC is the lowest concentration of the tested compound that inhibits the visible growth of the tested bacterial strain after overnight incubation while MBC is the lowest concentration of the tested compound required to kill the tested bacterium. Antibacterial agents are usually considered bactericidal if the MBC value doesn't exceed four folds the MIC value (French, 
2006). All the tested compounds showed MIC values higher than $40 \mu \mathrm{M}$ except compounds $\mathbf{4 a}$ and $\mathbf{4 c}$. Gentamicin and tetracycline were used in the test as reference drugs. The antibacterial activities of compounds $\mathbf{4 a}$ and $\mathbf{4 c}$ are presented in Table 1.

Based on the results, mentioned in Table 1, it was found that the presence of ethylester at position 5 on the 1,3-thiazolidin4-one ring is an essential feature for activity whereas the other congeners with 5-unsubstituted (compounds 3a-c) or 5-acetic acid side chain (compounds 5a-c) are devoid of activity. However, the nature of the substituent at position 3 was also critical for keeping compound activity as only the methyl and the phenyl substituents (compounds $\mathbf{4 a}$ and $\mathbf{4 c}$, respectively) were able to maintain the antibacterial activity. This was evidenced by compound $\mathbf{4 b}$ in which extending the methyl into ethyl led to complete loss of activity (compound 4a compared to compound 4b). Generally; compound 4c, with a phenyl substitution at position 3 of the 1,3thiazolidin-4-one nucleus, showed lower MIC values when compared with the MIC values of compound $\mathbf{4 a}$ with the 3-methyl substituent. In fact, in most cases, compound $\mathbf{4 c}$ showed a double potency compared to compound 4a. The higher activity of the more lipophilic ethylester derivatives $\mathbf{4 a}$ and $\mathbf{4 c}$ compared to the carboxylic acid derivatives $\mathbf{5 a}$ and $\mathbf{5 c}$ might be due to their higher ability to penetrate the bacterial outer membrane. Additionally, these ethylester derivatives might act as prodrugs which enhance the penetration of their carboxylic acid counterparts. However, this requires further investigations by testing the major form of the compounds existing in the bacterial cells after penetration of the compounds.

Compound $\mathbf{4 c}$ exhibited MIC values ranging from 5 to 20 $\mu \mathrm{M}$ against five different $S$. aureus strains and MIC values ranging from 2.5 to $10 \mu \mathrm{M}$ against three differentS. epidermidis strains. Compound 4calso showed an antibacterial activity against $E$. faecalis with MIC value of $2.5 \mu \mathrm{M}$ and MBC value of $5 \mu \mathrm{M}$. The potency of compound $\mathbf{4 c}$ against $E$. faecalisis significantly high when compared to the reference drug gentamicin, MIC value of gentamicin $=26.2 \mu \mathrm{M}$, showing that this compound is a potent bactericidal.

Most importantly, compounds $\mathbf{4 a}$ and $\mathbf{4 c}$ revealed antibacterial activity, not only against different Gram-positive pathogens, but also against the Gram-negative bacterium Y. pestis KUMA with MIC values of $10 \mu \mathrm{M}$ and $5 \mu \mathrm{M}$, respectively. On the other hand, none of the 2-(benzylidenehydrazono)-3arylthiazolidin-4-one derivatives, described in Scheme 2, showed antibacterial activity.

\section{Inhibition of biofilm formation}

Many microbes form biofilm in response to many factors in which cells stick to each other on a surface. These adherent cells are frequently embedded within a self-produced matrix of extracellular polymeric substance. The factors, by which biofilm is formed, may include cellular recognition of specific or nonspecific attachment sites on a surface. In some cases, the factors include the exposure of planktonic cells to sub-inhibitory concentrations of antibiotics. Biofilms are a serious problem for public health because of the increased resistance of biofilmassociated microorganisms to antimicrobial agents and the potential for these microorganisms to cause infections in patients with indwelling medical devices (Hoffman et al., 2005; Karatan and Watnick, 2009).

Unlike the antibacterial activity, the 2(benzylidenehydrazono)-3-arylthiazolidin-4-one derivatives $9 \mathbf{b}$ and 10a were able to inhibit the biofilm formation in $S$. epidermidis, where they showed $70 \%$ to $80 \%$ inhibition at a concentration of $40 \mu \mathrm{M}$. This highlighted the fact that this structure feature was crucial for biofilm inhibition activity. However, this was limited by the type of the substitution at position 4 of the 1,3-thiazolidin-4-one ring; where only the 4unsubstituted derivative $\mathbf{9 b}$ and the 4-ethoxycarbonyl derivative 10a were active as biofilm formation inhibitors. Generally, the presence of the acetic acid side chain at position 5 of the thiazolidinone ring (compounds $\mathbf{5 a - c}$ and 11a,b) resulted in analogues, lacking both antibacterial and biofilm inhibition activity.

\section{CONCLUSION}

We report herein the synthesis of new 1,3-thiazolidin-4one derivatives and their in vitro antibacterial activity. Based on the previous biological results, we can suggest that 1,3-thiazolidin4-one derivatives with an ethylester moiety at position 5 (compounds $\mathbf{4 a}$ and $\mathbf{4 c}$ ) are good lead compounds for further biological evaluation as antibacterial agents. Compounds $\mathbf{4 a}$ and 4c were not only active against different Gram-positive pathogens, but also against the Gram-negative bacterium $Y$. pestis. The antibacterial activity of compounds $\mathbf{4 a}$ and $\mathbf{4 c}$ can be due to the potential MurB inhibition activity of the thiazolidin-4-one nucleus. In addition, compounds $\mathbf{9 b}$ and $\mathbf{1 0 a}$ revealed biofilm inhibition activity against $S$. epidermidis biofilm formation. These obtained results are encouraging for further synthesis of new 1,3thiazolidin-4-one derivatives with different substitutions at positions 3 and 5, as potential antibacterial agents.

\section{EXPERIMENTAL}

\section{Chemical syntheses \\ Materials and methods}

${ }^{1} \mathrm{H}-\mathrm{NMR}$ and ${ }^{13} \mathrm{C}$-NMR spectra were recorded on an Avance 400 nuclear magnetic resonance spectrometer, Bruker Biospin GmbH Rheinstetten, Germany $\left({ }^{1} \mathrm{H} 400.123 \mathrm{MHz},{ }^{13} \mathrm{C}\right.$ $100.613 \mathrm{MHz}$ ). As an internal standard, the signals of the deuterated solvents were used (DMSO- $d_{6}:{ }^{1} \mathrm{H} 2.5 \mathrm{ppm},{ }^{13} \mathrm{C} 39.43$ $\mathrm{ppm})$. The following abbreviations describing the multiplicity are used: (s) singlet, (d) doublet, (t) triplet, (q) quartet, (dd) doublet of doublet. IR spectra were obtained with a Biorad Pharmalyz IR FTIR spectrometer (Biorad, Cambridge, MA, USA). Melting points were measured using an apparatus Sanyo Gallenkamp (Sanyo Gallenkamp, Loughborough, UK) and were not corrected. Elemental microanalyses were performed at the microanalytical center; Al-Azhar University, Cairo, Egypt. Thin layer 
chromatography (TLC) was carried out on TLC aluminum sheets, silica gel $\mathrm{F}_{254}$, (Merck KGaA, Darmstadt, Germany), and visualized in ultraviolet (UV) chamber. All chemicals were purchased from Sigma-Aldrich Chemicals (Deisenhofen, Germany), Acros Organics (Geel, Belgium) and VWR International (Darmstadt, Germany), and were used without further purification.

General procedures for the synthesis of 4-(3substitutedthioureido)benzenesulfonamides (2a-c)

The appropriate isothiocyanate $(12 \mathrm{mmol})$ was added to a solution of sulfanilamide $\mathbf{1}(10 \mathrm{mmol})$ in absolute ethanol $(20 \mathrm{~mL})$ then few drops of triethylamine were added to the solution and refluxed for $24 \mathrm{~h}$. A white precipitate was formed, filtered off, dried and recrystallized from ethanol to give compounds $\mathbf{2 a - c .}$

\section{4-(3-Methylthioureido)benzenesulfonamide (2a)}

Yield, 88\%; m.p. 222-224 ${ }^{\circ} \mathrm{C}$; IR, $\mathrm{cm}^{-1}: 3313,3294,3132$ $\left(\mathrm{NH}, \mathrm{NH}_{2}\right.$ ), 3055 (CH arom.), 2943, 2870 (CH aliph.), 1249 $(\mathrm{C}=\mathrm{S}), 1369,1161\left(\mathrm{SO}_{2}\right) .{ }^{1} \mathrm{H}-\mathrm{NMR}\left(\mathrm{DMSO}-d_{6}, \mathrm{ppm}\right) \delta: 2.94(\mathrm{~d}$, $\left.3 \mathrm{H}, \mathrm{CH}_{3}\right), 7.25\left(\mathrm{~s}, 2 \mathrm{H}, \mathrm{SO}_{2} \mathrm{NH}_{2}\right.$, exchangeable with $\left.\mathrm{D}_{2} \mathrm{O}\right), 7.62(\mathrm{~d}$, $2 \mathrm{H}, J=8.51 \mathrm{~Hz}, \mathrm{CH}_{\text {arom. }}$ ), 7.74 (d, 2H, J=8.95 Hz, $\mathrm{CH}_{\text {arom. }}$ ), 7.97 (s, $1 \mathrm{H}, \mathrm{NH}$, exchangeable with $\left.\mathrm{D}_{2} \mathrm{O}\right), 9.84(\mathrm{~s}, 1 \mathrm{H}, \mathrm{NH}$, exchangeable with $\left.\mathrm{D}_{2} \mathrm{O}\right) .{ }^{13} \mathrm{C}-\mathrm{NMR}$ (DMSO- $\left.d_{6}, \mathrm{ppm}\right) \delta$ : $31.07\left(\mathrm{CH}_{3}\right), 121.46$, $126.21,138.36,142.59\left(\underline{\mathrm{CH}}_{\text {arom. }}\right), 180.98(\underline{\mathrm{C}}=\mathrm{S})$.

\section{4-(3-Ethylthioureido)benzenesulfonamide (2b)}

Yield, 92\%; m.p. 209-211 ${ }^{\circ} \mathrm{C}$; IR, $\mathrm{cm}^{-1}:$ 3352, 3298, 3155 (NH, $\mathrm{NH}_{2}$ ), 3062 (CH arom.), 2974, 2890 (CH aliph.), 1249 $(\mathrm{C}=\mathrm{S}), 1377,1165\left(\mathrm{SO}_{2}\right) .{ }^{1} \mathrm{H}-\mathrm{NMR}$ (DMSO-d $\left.d_{6}, \mathrm{ppm}\right) \delta: 1.19(\mathrm{t}$, $3 \mathrm{H}, J=7.91 \mathrm{~Hz}, \mathrm{CH}_{3}$ ), 3.45 (q, 2H, J=7.09 Hz, $\mathrm{CH}_{2}$ ), 7.23 (s, 2H, $\mathrm{SO}_{2} \mathrm{NH}_{2}$ ), 7.61 (d, 2H, $\left.J=8.62 \mathrm{~Hz}, \mathrm{CH}_{\text {arom. }}\right), 7.73$ (d, 2H, $J=8.9$ $\left.\mathrm{Hz}, \mathrm{CH}_{\text {arom. }}\right), 7.95$ (s, 1H, NH), $9.82(\mathrm{~s}, 1 \mathrm{H}, \mathrm{NH}) .{ }^{13} \mathrm{C}-\mathrm{NMR}$ (DMSO-d $\left.d_{6}, \mathrm{ppm}\right) \delta: 13.92\left(\underline{\mathrm{CH}}_{3}\right), 25.46\left(\underline{\mathrm{CH}}_{2}\right), 121.50,126.21$, $138.38,142.69\left(\underline{\mathrm{CH}}_{\text {arom }}\right), 179.99(\underline{\mathrm{C}}=\mathrm{S})$.

\section{4-(3-Phenylthioureido)benzenesulfonamide (2c)}

Yield, 86\%; m.p. $204-206{ }^{\circ} \mathrm{C}$; IR, $\mathrm{cm}^{-1}: 3344,3240,3165$ ( $\mathrm{NH}, \mathrm{NH}_{2}$ ), 3008 (CH arom.), $1242(\mathrm{C}=\mathrm{S}), 1334,1157\left(\mathrm{SO}_{2}\right) .{ }^{1} \mathrm{H}-$ NMR (DMSO- $\left.d_{6}, \mathrm{ppm}\right) \delta: 7.15\left(\mathrm{dd}, 1 \mathrm{H}, \mathrm{CH}_{\text {arom. }}\right), 7.28(\mathrm{~s}, 2 \mathrm{H}$, $\mathrm{SO}_{2} \mathrm{NH}_{2}$ ), 7.35 (dd, 2H, $\mathrm{CH}_{\text {arom. }}$ ), 7.49 (d, 2H, $\mathrm{CH}_{\text {arom. }}$ ), 7.70 (d, $2 \mathrm{H}, J=8.73 \mathrm{~Hz}, \mathrm{CH}_{\text {arom.) }} 7.75$ (d, $\left.2 \mathrm{H}, J=8.61 \mathrm{~Hz}, \mathrm{CH}_{\text {arom. }}\right), 10.02$ $(\mathrm{s}, 1 \mathrm{H}, \mathrm{NH}), 10.05(\mathrm{~s}, 1 \mathrm{H}, \mathrm{NH}) .{ }^{13} \mathrm{C}-\mathrm{NMR}$ (DMSO- $\left.d_{6}, \mathrm{ppm}\right) \delta$ : $122.30,122.49,123.60,124.63,126.03,128.43,139.07,142.57$ $\left(\underline{\mathrm{CH}}_{\text {arom. }}\right), 179.48(\underline{\mathrm{C}}=\mathrm{S})$.

General procedures for the synthesis of 4-(4-oxo-3-substitutedthiazolidin-2-ylideneamino)benzenesulfonamides (3a-c)

$10 \mathrm{mmol}$ of monochloroacetic acid and a catalytic amount of anhydrous sodium acetate were added to a solution of compound $\mathbf{2 a}, \mathbf{2 b}$ or $\mathbf{2 c}(10 \mathrm{mmol})$ in glacial acetic acid $(20 \mathrm{~mL})$. The mixture was refluxed for $24 \mathrm{~h}$ and left to cool then poured into crushed ice. The formed precipitate was filtered off and crystallized from ethanol to give the corresponding 1,3-thiazolidin4-one derivatives 3a-c.

4-(3-Methyl-4-oxo- thiazolidin- 2-ylideneamino benzenesulfonamide (3a)

Yield, 58\%; m.p. 183-185 ${ }^{\circ} \mathrm{C}$; IR, $\mathrm{cm}^{-1}: 3332,3221$ $\left(\mathrm{NH}_{2}\right), 3097$ ( $\mathrm{CH}$ arom.), 2943, 2851 ( $\mathrm{CH}$ aliph.), $1712(\mathrm{C}=\mathrm{O})$, $1620(\mathrm{C}=\mathrm{N}), 1377,1153\left(\mathrm{SO}_{2}\right) .{ }^{1} \mathrm{H}-\mathrm{NMR}$ (DMSO-d $\left.d_{6}, \mathrm{ppm}\right) \delta: 3.17$ $\left(\mathrm{s}, 3 \mathrm{H}, \mathrm{N}-\mathrm{CH}_{3}\right), 4.06\left(\mathrm{~s}, 2 \mathrm{H}, \mathrm{CH}_{2}\right), 7.09(\mathrm{~d}, 2 \mathrm{H}, J=8.51 \mathrm{~Hz}$, $\mathrm{CH}_{\text {arom. }}$ ), 7.31 (s. $2 \mathrm{H}, \mathrm{SO}_{2} \mathrm{NH}_{2}$, exchangeable with $\mathrm{D}_{2} \mathrm{O}$ ), 7.80 (d, $2 \mathrm{H}, J=8.82 \mathrm{~Hz}, \mathrm{CH}_{\text {arom. }}$ ). ${ }^{13} \mathrm{C}-\mathrm{NMR}$ (DMSO-d $\left.d_{6}, \mathrm{ppm}\right) \delta: 29.07$ $\left(\underline{\mathrm{CH}}_{2}\right), 32.74\left(\underline{\mathrm{CH}}_{3}\right), 121.16,127.06,139.62,151.12\left(\underline{\mathrm{CH}}_{\text {arom}}\right)$, $156.89(\mathrm{~N}=\underline{\mathrm{C}}), 171.80(\underline{\mathrm{C}}=\mathrm{O})$. Anal. Calcd. For $\mathrm{C}_{10} \mathrm{H}_{11} \mathrm{~N}_{3} \mathrm{O}_{3} \mathrm{~S}_{2}$ (285.34): C, 42.09; H, 3.89; N, 14.73. Found: C, 42.21; H, 3.93; N, 14.90 .

4-(3-Ethyl-4-oxo-thiazolidin-2-ylideneamino) benzenesulfonamide (3b)

Yield, 64\%; m.p. 169-171 ${ }^{\circ} \mathrm{C}$; IR, $\mathrm{cm}^{-1}: 3329,3255$ $\left(\mathrm{NH}_{2}\right), 3080$ (CH arom.), 2983, 2860 ( $\mathrm{CH}$ aliph.), $1732(\mathrm{C}=\mathrm{O})$, $1643(\mathrm{C}=\mathrm{N}), 1373,1168\left(\mathrm{SO}_{2}\right) .{ }^{1} \mathrm{H}-\mathrm{NMR}\left(\mathrm{DMSO}-d_{6}, \mathrm{ppm}\right) \delta: 1.21$ (t, 3H, J= $\left.7.11 \mathrm{~Hz}, \mathrm{CH}_{3}\right), 3.81\left(\mathrm{q}, 2 \mathrm{H}, J=7.17 \mathrm{~Hz}, \mathrm{CH}_{3}\right), 4.04$ (s, $2 \mathrm{H}, \mathrm{CH}_{2}$ ), 7.09 (d, 2H, J=8.49 Hz, $\mathrm{CH}_{\text {arom. }}$ ), 7.31 (s. $2 \mathrm{H}, \mathrm{SO}_{2} \mathrm{NH}_{2}$ ), $7.81\left(\mathrm{~d}, 2 \mathrm{H}, J=8.91 \mathrm{~Hz}, \mathrm{CH}_{\text {arom. }}\right) .{ }^{13} \mathrm{C}-\mathrm{NMR}$ (DMSO- $\left.d_{6}, \mathrm{ppm}\right) \delta$ : $12.21\left(\mathrm{CH}_{2} \mathrm{CH}_{3}\right), 32.73\left(\underline{\mathrm{CH}}_{2}-\mathrm{C}=\mathrm{O}\right), 37.42\left(\underline{\mathrm{CH}}_{2} \mathrm{CH}_{3}\right), 121.25$, 127.13, 139.71, 151.19 ( $\left.\underline{\mathrm{CH}}_{\text {arom}}\right), 156.11(\mathrm{~N}=\underline{\mathrm{C}}), 171.64(\underline{\mathrm{C}}=\mathrm{O})$. Anal. Calcd. For $\mathrm{C}_{11} \mathrm{H}_{13} \mathrm{~N}_{3} \mathrm{O}_{3} \mathrm{~S}_{2}$ (299.37): C, 44.13; H, 4.38; N, 14.04. Found: C, 44.22; H, 4.39; N, 14.15.

\section{4-(4-Oxo-3 -phenylthiazolidin- 2-ylideneamino)}

benzenesulfonamide (3c)

Yield, 60\%; m.p. 190-192 ${ }^{\circ} \mathrm{C}$; IR, $\mathrm{cm}^{-1}$ : 3363, $3204\left(\mathrm{NH}_{2}\right), 3051$ (CH arom.), $1724(\mathrm{C}=\mathrm{O}), 1635(\mathrm{C}=\mathrm{N}), 1373,1153\left(\mathrm{SO}_{2}\right) .{ }^{1} \mathrm{H}-$ NMR (DMSO- $\left.d_{6}, \mathrm{ppm}\right) \delta: 4.16\left(\mathrm{~s}, 2 \mathrm{H}, \mathrm{CH}_{2}\right), 6.88\left(\mathrm{~d}, 2 \mathrm{H}, \mathrm{CH}_{\text {arom}}\right)$, 7.09 (dd, 1H, $\mathrm{CH}_{\text {arom. }}$ ), 7.34 (dd, 2H, $\mathrm{CH}_{\text {arom. }}$ ), 7.42 (d, 2H, J= 8.88 $\mathrm{Hz}, \mathrm{CH}_{\text {arom. }}$ ), 7.45 (s, 2H, $\mathrm{SO}_{2} \mathrm{NH}_{2}$ ), 7.53 (d, $2 \mathrm{H}, J=8.97 \mathrm{~Hz}$, $\left.\mathrm{CH}_{\text {arom. }}\right) .{ }^{13} \mathrm{C}-\mathrm{NMR}$ (DMSO-d $\left.d_{6}, \mathrm{ppm}\right) \delta: 32.74\left(\mathrm{CH}_{2}\right), 122.55$, $124.09,128.36,128.89,129.13,135.19,148.06,155.78\left(\underline{\mathrm{CH}}_{\text {arom. }}\right)$, $171.54(\mathrm{~N}=\underline{\mathrm{C}}), 172.57(\underline{\mathrm{C}}=\mathrm{O})$. Anal. Calcd. For $\mathrm{C}_{15} \mathrm{H}_{13} \mathrm{~N}_{3} \mathrm{O}_{3} \mathrm{~S}_{2}$ (347.41): C, 51.86; H, 3.77; N, 12.10. Found: C, 51.98; H, 3.75; N, 12.27 .

General procedures for the synthesis of ethyl 4-oxo-3-substituted2-(4-sulfamoylphenylimino)thiazolidine-5-carboxylates (4a-c)

$10 \mathrm{mmol}$ of diethylbromomalonate and a catalytic amount of anhydrous sodium acetate were added to a solution of compound $\mathbf{2 a}, \mathbf{2 b}$ or $\mathbf{2 c}(10 \mathbf{m m o l})$ in glacial acetic acid $(20 \mathrm{~mL})$. The mixture was refluxed for $24 \mathrm{~h}$ and left to cool then poured into crushed ice. The formed precipitate was filtered off and crystallized from ethanol to give the corresponding 1,3thiazolidin-4-one derivatives 4a-c. 
Ethyl 3-methyl-4-oxo-2-(4-sulfamoylphenylimino)thiazolidine-5carboxylate $\mathbf{( 4 a )}$

Yield, 46\%; m.p. 106-108 ${ }^{\circ} \mathrm{C}$; IR, $\mathrm{cm}^{-1}$ : 3356, 3255 $\left(\mathrm{NH}_{2}\right), 3070$ (CH arom.), 2978, 2870 (CH aliph.), 1724, 1698 $(2 \mathrm{C}=\mathrm{O}), 1369,1157\left(\mathrm{SO}_{2}\right) .{ }^{1} \mathrm{H}-\mathrm{NMR}\left(\mathrm{DMSO}-d_{6}, \mathrm{ppm}\right) \delta: 1.25(\mathrm{t}$, $\left.3 \mathrm{H}, J=7.21 \mathrm{~Hz}, \mathrm{CH}_{3}\right), 3.19$ (s, 3H, $\left.\mathrm{CH}_{3}\right), 3.72$ (q, 2H, $J=7.03 \mathrm{~Hz}$, $\mathrm{CH}_{2}$ ), 4.10 (s, 1H, CH), 7.09 (d, 2H, J=8.63 Hz, $\mathrm{CH}_{\text {arom. }}$ ), 7.32 (s, $\left.2 \mathrm{H}, \mathrm{SO}_{2} \mathrm{NH}_{2}\right), 7.82\left(\mathrm{~d}, 2 \mathrm{H}, J=8.72 \mathrm{~Hz}, \mathrm{CH}_{\text {arom. }}\right) .{ }^{13} \mathrm{C}-\mathrm{NMR}$ $\left(\mathrm{DMSO}-d_{6}, \mathrm{ppm}\right) \delta$ : $13.52\left(\mathrm{COOCH}_{2} \underline{\mathrm{CH}}_{3}\right), 21.90\left(\mathrm{~N}_{-} \mathrm{CH}_{3}\right), 29.15$ $(\mathrm{H} \underline{\mathrm{C}}-\mathrm{C}=\mathrm{O}), 32.81\left(\mathrm{COOC}_{2} \mathrm{CH}_{3}\right), 121.24,127.14,139.70,151.20$ $\left(\underline{\mathrm{CH}}_{\text {arom }}\right), 155.51(\mathrm{~N}=\underline{\mathrm{C}}), 171.05\left(\underline{\mathrm{COOCH}}_{2} \mathrm{CH}_{3}\right), 171.89(\mathrm{~N}-\underline{\mathrm{C}}=\mathrm{O})$. Anal. Calcd. For $\mathrm{C}_{13} \mathrm{H}_{15} \mathrm{~N}_{3} \mathrm{O}_{5} \mathrm{~S}_{2}$ (357.41): C, 43.69; H, 4.23; N, 11.76. Found: C, 43.77; H, 4.25; N, 11.85 .

Ethyl 3-ethyl-4-oxo-2-(4-sulfamoylphenylimino)thiazolidine-5carboxylate (4b)

Yield, 40\%; m.p. 159-161 ${ }^{\circ} \mathrm{C}$; IR, $\mathrm{cm}^{-1}$ : 3544, 3461 $\left(\mathrm{NH}_{2}\right), 3070$ (CH arom.), 2989, 2877 (CH aliph.), 1751, 1721 $(2 \mathrm{C}=\mathrm{O}), 1390,1198\left(\mathrm{SO}_{2}\right) .{ }^{1} \mathrm{H}-\mathrm{NMR}\left(\mathrm{DMSO}-d_{6}, \mathrm{ppm}\right) \delta: 1.13(\mathrm{t}$, $\left.3 \mathrm{H}, J=7.18 \mathrm{~Hz}, \mathrm{CH}_{3}\right), 1.19$ (t, 3H, J=7.34 Hz, $\left.\mathrm{CH}_{3}\right), 3.74$ (q, 2H, $J=7.51 \mathrm{~Hz}, \mathrm{CH}_{2}$ ), 3.84 (q, 2H, J=7.42 Hz, $\mathrm{CH}_{2}$ ), 4.05 (s, 1H, CH), 7.09 (d, 2H, J= 8.59 Hz, $\mathrm{CH}_{\text {arom.) }}, 7.79$ (s, 2H, $\mathrm{SO}_{2} \mathrm{NH}_{2}$ ), 7.84 (d, $2 \mathrm{H}, J=8.79 \mathrm{~Hz}, \mathrm{CH}_{\text {arom. }}$ ). ${ }^{13} \mathrm{C}-\mathrm{NMR}$ (DMSO- $\left.d_{6}, \mathrm{ppm}\right) \delta: 11.24$ $\left(\underline{\mathrm{CH}}_{3} \mathrm{CH}_{2}\right), 13.41\left(\mathrm{COOCH}_{2} \underline{\mathrm{CH}_{3}}\right), 34.96\left(\mathrm{CH}_{3} \underline{\mathrm{CH}}_{2}\right), 56.42(\mathrm{H} \underline{\mathrm{C}}-$ $\mathrm{C}=\mathrm{O}), 64.21\left(\mathrm{COOCH}_{2} \mathrm{CH}_{3}\right), 121.22,127.44,133.57,140.57$ $\left(\underline{\mathrm{C}} \mathrm{H}_{\text {arom }}\right), 155.29(\mathrm{~N}=\underline{\mathrm{C}}), 164.78\left(\underline{\mathrm{COOCH}}_{2} \mathrm{CH}_{3}\right), 168.96(\mathrm{~N}-\underline{\mathrm{C}}=\mathrm{O})$. Anal. Calcd. For $\mathrm{C}_{14} \mathrm{H}_{17} \mathrm{~N}_{3} \mathrm{O}_{5} \mathrm{~S}_{2}$ (371.43): C, 45.27; H, 4.61; N, 11.31. Found: C, 45.39; H, 4.69; N, 11.46.

Ethyl 4-oxo-3-phenyl-2-(4-sulfamoylphenylimino)thiazolidine-5carboxylate (4c)

Yield, 53\%; m.p. 126-128 ${ }^{\circ} \mathrm{C}$; IR, $\mathrm{cm}^{-1}$ : 3356, 3259 $\left(\mathrm{NH}_{2}\right), 3062$ (CH arom.), 2981, 2871 (CH aliph.), 1728, 1701 $(2 \mathrm{C}=\mathrm{O}), 1369,1153\left(\mathrm{SO}_{2}\right) .{ }^{1} \mathrm{H}-\mathrm{NMR}$ (DMSO-d $\left.6, \mathrm{ppm}\right) \delta: 1.23(\mathrm{t}$, $\left.3 \mathrm{H}, J=7.65 \mathrm{~Hz}, \mathrm{CH}_{3}\right), 4.21$ (q, 2H, J=7.71 Hz, $\left.\mathrm{CH}_{2}\right), 4.32$ (s, $1 \mathrm{H}$, $\mathrm{CH}$ ), 6.87 (dd, 1H, $\mathrm{CH}_{\text {arom. }}$ ), 7.04 (dd, 2H, $\mathrm{CH}_{\text {arom. }}$ ), 7.29 (d, 2H, $\mathrm{CH}_{\text {arom. }}$ ), 7.41 (d, $2 \mathrm{H}, J=8.80 \mathrm{~Hz}, \mathrm{CH}_{\text {arom. }}$ ), 7.52 (s, $2 \mathrm{H}, \mathrm{SO}_{2} \mathrm{NH}_{2}$ ), $7.76\left(\mathrm{~d}, 2 \mathrm{H}, J=8.91 \mathrm{~Hz}, \mathrm{CH}_{\text {arom. }}\right.$ ). ${ }^{13} \mathrm{C}-\mathrm{NMR}$ (DMSO- $\left.d_{6}, \mathrm{ppm}\right) \delta$ : $13.86\left(\mathrm{COOCH}_{2} \underline{\mathrm{CH}_{3}}\right), 28.62(\mathrm{HC}-\mathrm{C}=\mathrm{O}), 32.75\left(\mathrm{COOCH}_{2} \mathrm{CH}_{3}\right)$, $120.55,120.94,124.10,127.02,128.37,128.90,129.15,129.54$ $\left(\underline{\mathrm{CH}}_{\text {arom. }}\right), 154.95(\mathrm{~N}=\underline{\mathrm{C}}), 170.91\left(\underline{\mathrm{COOCH}}_{2} \mathrm{CH}_{3}\right), 171.50(\mathrm{~N}-\underline{\mathrm{C}}=\mathrm{O})$. Anal. Calcd. For $\mathrm{C}_{18} \mathrm{H}_{17} \mathrm{~N}_{3} \mathrm{O}_{5} \mathrm{~S}_{2}$ (419.47): C, 51.54; H, 4.08; N, 10.02. Found: C, 51.63; H, 4.11; N, 10.09.

General procedures for the synthesis of 2-(4-oxo-3-substituted-2(4-sulfamoylphenylimino)thiazolidin-5-yl)acetic acids (5a-c)

$10 \mathrm{mmol}$ of maleic anhydride was added to a solution of compound $\mathbf{2 a}, \mathbf{2 b}$ or $\mathbf{2 c}(10 \mathrm{mmol})$ in glacial acetic acid $(20 \mathrm{~mL})$, The mixture was refluxed for $24 \mathrm{~h}$ and left to cool then poured into crushed ice. The formed precipitate was filtered off and crystallized from ethanol to give the corresponding 1,3thiazolidin-4-one derivatives 5a-c.
2-(3-Methyl-4-oxo-2-(4-sulfamoylphenylimino)thiazolidin-5yl)acetic acid (5a)

Yield, 61\%; m.p. $160-162{ }^{\circ} \mathrm{C}$; IR, $\mathrm{cm}^{-1}$ : 3356, 3205 $\left(\mathrm{NH}_{2}\right), 3100(\mathrm{OH}), 3052$ ( $\mathrm{CH}$ arom.), 2985, 2878 ( $\mathrm{CH}$ aliph.), 1697, $1674(2 \mathrm{C}=\mathrm{O}), 1370,1157\left(\mathrm{SO}_{2}\right) .{ }^{1} \mathrm{H}-\mathrm{NMR}$ (DMSO- $\left.d_{6}, \mathrm{ppm}\right)$ $\delta: 1.95\left(\mathrm{~d}, 2 \mathrm{H}, J=6.52 \mathrm{~Hz}, \mathrm{CH}_{2}\right), 3.21\left(\mathrm{~s}, 3 \mathrm{H}, \mathrm{CH}_{3}\right), 4.54(\mathrm{t}, 1 \mathrm{H}, J=$ $6.79 \mathrm{~Hz}, \mathrm{CH}), 7.05$ (d, 2H, J= $\left.8.69 \mathrm{~Hz}, \mathrm{CH}_{\text {arom. }}\right), 7.71(\mathrm{~s}, 2 \mathrm{H}$, $\mathrm{SO}_{2} \mathrm{NH}_{2}$ ), 7.80 (d, 2H, J=8.99 Hz, $\mathrm{CH}_{\text {arom }}$ ), 10.56 (s, 1H, OH). ${ }^{13} \mathrm{C}-\mathrm{NMR}$ (DMSO- $d_{6}$, ppm) $\delta: 21.03\left(\mathrm{~N}-\underline{\mathrm{CH}}_{3}\right), 29.19\left(\mathrm{CH}_{2}\right), 43.58$ $(\mathrm{HC}-\mathrm{C}=\mathrm{O}), 118.39,126.71,138.53,151.32\left(\underline{\mathrm{CH}}_{\text {arom. }}\right), 156.89$ ($\mathrm{N}=\underline{\mathrm{C}}), \quad 168.45(\underline{\mathrm{COOH}}), 173.72 \quad(\underline{\mathrm{C}}=\mathrm{O})$. Anal. Calcd. For $\mathrm{C}_{12} \mathrm{H}_{13} \mathrm{~N}_{3} \mathrm{O}_{5} \mathrm{~S}_{2}$ (343.38): C, 41.97; H, 3.82; N, 12.24. Found: C, 42.08; H, 3.80; N, 12.38 .

2-(3-Ethyl-4-oxo-2-(4-sulfamoylphenylimino) thiazolidin-5-

$y$ l)acetic acid (5b)

Yield, 61\%; m.p. $188-190{ }^{\circ} \mathrm{C}$; IR, $\mathrm{cm}^{-1}$ : 3352, 3263 $\left(\mathrm{NH}_{2}\right), 3113(\mathrm{OH}), 3052$ (CH arom.), 2997, 2865 (CH aliph.), 1701, $1658(2 \mathrm{C}=\mathrm{O}), 1334,1157\left(\mathrm{SO}_{2}\right) .{ }^{1} \mathrm{H}-\mathrm{NMR}\left(\mathrm{DMSO}-d_{6}, \mathrm{ppm}\right)$ $\delta: 1.21\left(\mathrm{t}, 3 \mathrm{H}, J=7.33 \mathrm{~Hz}, \mathrm{CH}_{3}\right), 1.81\left(\mathrm{~d}, 2 \mathrm{H}, J=7.01 \mathrm{~Hz}, \mathrm{CH}_{2}\right)$, $3.80\left(\mathrm{q}, 2 \mathrm{H}, J=7.64 \mathrm{~Hz}, \mathrm{CH}_{2}\right), 4.29(\mathrm{t}, 1 \mathrm{H}, J=6.91 \mathrm{~Hz}, \mathrm{CH}), 7.09$ (d, $2 \mathrm{H}, J=8.90 \mathrm{~Hz}, \mathrm{CH}_{\text {arom }}$ ), 7.72 (s, $\left.2 \mathrm{H}, \mathrm{SO}_{2} \mathrm{NH}_{2}\right), 7.78$ (d, $2 \mathrm{H}, J=$ $9.0 \mathrm{~Hz}, \mathrm{CH}_{\text {arom. }}$ ), 10.49 (s, $\left.1 \mathrm{H}, \mathrm{OH}\right) .{ }^{13} \mathrm{C}-\mathrm{NMR}$ (DMSO-d $\left.d_{6}, \mathrm{ppm}\right) \delta$ : $12.14\left(\underline{\mathrm{CH}}_{3} \mathrm{CH}_{2}\right), 22.36\left(\underline{\mathrm{CH}_{2}}\right), 38.45\left(\mathrm{CH}_{3} \underline{\mathrm{CH}}_{2}\right), 43.50(\mathrm{H} \underline{\mathrm{C}}-\mathrm{C}=\mathrm{O})$, 121.30, 127.07, 139.63, $141.52\left(\underline{\mathrm{CH}}_{\text {arom. }}\right), 155.93(-\mathrm{N}=\underline{\mathrm{C}}), 168.40$ $(\underline{\mathrm{COOH}}), \quad 172.97(\underline{\mathrm{C}}=\mathrm{O})$. Anal. Calcd. For $\mathrm{C}_{13} \mathrm{H}_{15} \mathrm{~N}_{3} \mathrm{O}_{5} \mathrm{~S}_{2}$ (357.41): C, 43.69; H, 4.23; N, 11.76. Found: C, 43.77; H, 4.27; N, 11.83 .

2-(4-Oxo-3-phenyl-2-(4-sulfamoylphenylimino)thiazolidin-5yl)acetic acid (5c)

Yield, 63\%; m.p. $171-173{ }^{\circ} \mathrm{C}$; IR, $\mathrm{cm}^{-1}$ : 3348, 3300 $\left(\mathrm{NH}_{2}\right), 3215(\mathrm{OH}), 3066$ (CH arom.), 2931, 2875 (CH aliph.), 1708, $1660(2 \mathrm{C}=\mathrm{O}), 1388,1161\left(\mathrm{SO}_{2}\right) .{ }^{1} \mathrm{H}-\mathrm{NMR}\left(\mathrm{DMSO}-d_{6}, \mathrm{ppm}\right)$ $\delta: 1.91\left(\mathrm{~d}, 2 \mathrm{H}, J=6.64 \mathrm{~Hz}, \mathrm{CH}_{2}\right), 4.49(\mathrm{t}, 1 \mathrm{H}, J=6.75 \mathrm{~Hz}, \mathrm{CH})$, 6.87 (dd, 1H, $\mathrm{CH}_{\text {arom. }}$ ), 7.03 (dd, 2H, $\mathrm{CH}_{\text {arom. }}$ ), 7.29 (d, 2H, $\mathrm{CH}_{\text {arom. }}$ ), 7.46 (d, 2H, J= $8.92 \mathrm{~Hz}, \mathrm{CH}_{\text {arom }}$ ), 7.74 (s, 2H, $\mathrm{SO}_{2} \mathrm{NH}_{2}$ ), $7.95\left(\mathrm{~d}, 2 \mathrm{H}, J=8.83 \mathrm{~Hz}, \mathrm{CH}_{\text {arom. }}\right), 10.35$ (s, 1H, OH). ${ }^{13} \mathrm{C}-\mathrm{NMR}$ $\left(\mathrm{DMSO}-d_{6}, \mathrm{ppm}\right) \delta: 21.02\left(\underline{\mathrm{CH}}_{2}\right), 43.62(\mathrm{HC}-\mathrm{C}=\mathrm{O}), 120.71$, $121.09,122.93,127.05,128.47,128.92,129.18,139.54\left(\underline{\mathrm{CH}}_{\text {arom. }}\right)$, $155.82(-\mathrm{N}=\underline{\mathrm{C}}), 168.86(\underline{\mathrm{COOH}}), 171.97(\underline{\mathrm{C}}=\mathrm{O})$. Anal. Calcd. For $\mathrm{C}_{17} \mathrm{H}_{15} \mathrm{~N}_{3} \mathrm{O}_{5} \mathrm{~S}_{2}$ (405.45): C, 50.36; H, 3.73; N, 10.36. Found: C, $50.49 ; \mathrm{H}, 3.71 ; \mathrm{N}, 10.44$.

\section{Synthesis of 4-isothiocyanatobenzenesulfonamide (6)}

A solution of sulfanilamide $\mathbf{1}$ in water was prepared by stirring sulfanilamide $1(10 \mathrm{mmol})$ in distilled water $(40 \mathrm{~mL})$, containing hydrochloric acid $(10 \mathrm{mmol})$, for $5 \mathrm{~min}$. Thiophosgen (10 $\mathrm{mmol}$ ) was added to the prepared solution and the mixture was stirred at room temperature for $2 \mathrm{~h}$. The formed precipitate was filtered off and dried to give compounds 6 (El-Gaby et al., 2009). 
Synthesis of N-(4-sulfamoylphenyl)hydrazinecarbothioamide (7)

A mixture, of compound $6(10 \mathrm{mmol})$ and excess amount of hydrazine hydrate in isopropanol $(40 \mathrm{~mL})$, was stirred at room temperature for 4 hours. The formed precipitate was filtered off and dried to give compound 7 (Sriram et al., 2009).

General procedures for the synthesis of 2-(4-(substituted) benzylidene)- $N$ - (4-sulfamoylphenyl) hydrazinecarbothioamides $(\mathbf{8 a}, \mathbf{b})$

A mixture, of compound $7(10 \mathrm{mmol})$ and the appropriate aldehyde $(10 \mathrm{mmol})$ in methanol $(30 \mathrm{~mL})$, was refluxed for $5 \mathrm{~h}$. The formed precipitate was filtered, while hot, and the obtained solid was dried to give compounds $\mathbf{8 a}, \mathbf{b}$.

\section{2-(4-Chorobenzylidene)- $N$-(4-sulfamoylphenyl)}

hydrazinecarbothioamide (8a)

Yield, 59\%; m.p. 240-242 ${ }^{\circ} \mathrm{C}$; IR, $\mathrm{cm}^{-1}$ : 3288, 3245, 3131 ( $\mathrm{NH}, \mathrm{NH}_{2}$ ), 3089 (CH arom.), 2978, 2873 (CH aliph.), 1587 $(\mathrm{C}=\mathrm{N}), 1278(\mathrm{C}=\mathrm{S}), 1393,1158\left(\mathrm{SO}_{2}\right) .{ }^{1} \mathrm{H}-\mathrm{NMR}$ (DMSO- $\left.d_{6}, \mathrm{ppm}\right)$ $\delta: 6.70\left(\mathrm{~d}, 2 \mathrm{H}, J=8.48 \mathrm{~Hz}, \mathrm{CH}_{\text {arom. }}\right), 7.25\left(\mathrm{~s}, 2 \mathrm{H}, \mathrm{SO}_{2} \mathrm{NH}_{2}\right.$, exchangeable with $\left.\mathrm{D}_{2} \mathrm{O}\right), 7.56\left(\mathrm{~d}, 2 \mathrm{H}, J=8.84 \mathrm{~Hz}, \mathrm{CH}_{\text {arom. }}\right), 7.82$ (d, 2H, J=8.74 Hz, $\mathrm{CH}_{\text {arom. }}$ ), 7.98 (d, 2H, J=8.72 Hz, $\mathrm{CH}_{\text {arom.), }}$ ), $8.15(\mathrm{~s}, 1 \mathrm{H},-\mathrm{N}=\mathrm{CH}), 10.32$ (s, $1 \mathrm{H}, \mathrm{NH}$, exchangeable with $\left.\mathrm{D}_{2} \mathrm{O}\right)$, $12.05\left(\mathrm{~s}, 1 \mathrm{H}, \mathrm{NH}\right.$, exchangeable with $\mathrm{D}_{2} \mathrm{O}$ ). ${ }^{13} \mathrm{C}-\mathrm{NMR}$ (DMSO- $d_{6}$, ppm) $\delta: 125.42,125.63,129.07,130.00,132.82,134.63,140.35$, $142.01\left(\underline{\mathrm{CH}}_{\text {arom. }}\right), 142.15(\mathrm{~N}=\underline{\mathrm{CH}}), 175.93(\underline{\mathrm{C}}=\mathrm{S})$. Anal. Calcd. For $\mathrm{C}_{14} \mathrm{H}_{13} \mathrm{ClN}_{4} \mathrm{O}_{2} \mathrm{~S}_{2}$ (368.86): $\mathrm{C}, 45.59 ; \mathrm{H}, 3.55$; N, 15.19. Found: $\mathrm{C}$, $45.65 ; \mathrm{H}, 3.58 ; \mathrm{N}, 15.32$.

\section{2-(4-(Dimethylamino)benzylidene)- N-(4-sulfamoylphenyl) \\ hydrazinecarbothioamide $\mathbf{( 8 \mathbf { b } )}$}

Yield, 55\%; m.p. $225-227{ }^{\circ} \mathrm{C}$; IR, $\mathrm{cm}^{-1}$ : 3333, 3245, 3135 ( $\mathrm{NH}, \mathrm{NH}_{2}$ ), 3090 (CH arom.), 2974, 2899 (CH aliph.), 1587 $(\mathrm{C}=\mathrm{N}), 1268(\mathrm{C}=\mathrm{S}), 1364,1154\left(\mathrm{SO}_{2}\right) .{ }^{1} \mathrm{H}-\mathrm{NMR}$ (DMSO- $\left.d_{6}, \mathrm{ppm}\right)$ $\delta: 2.98\left(\mathrm{~s}, 6 \mathrm{H}, \mathrm{N}\left(\mathrm{CH}_{3}\right)_{2}\right), 6.73\left(\mathrm{~d}, 2 \mathrm{H}, J=8.51 \mathrm{~Hz}, \mathrm{CH}_{\text {arom }}\right), 7.32$ (s, $\left.2 \mathrm{H}, \mathrm{SO}_{2} \mathrm{NH}_{2}\right), 7.70\left(\mathrm{~d}, 2 \mathrm{H}, J=8.56 \mathrm{~Hz}, \mathrm{CH}_{\text {arom. }}\right), 7.78$ (d, 2H, J= $\left.8.81 \mathrm{~Hz}, \mathrm{CH}_{\text {arom. }}\right), 7.86\left(\mathrm{~d}, 2 \mathrm{H}, J=8.89 \mathrm{~Hz}, \mathrm{CH}_{\text {arom. }}\right), 8.06$ (s, $1 \mathrm{H}$, $\mathrm{N}=\mathrm{CH}), 10.10$ (s, 1H, NH), 11.76 (s, 1H, NH). ${ }^{13} \mathrm{C}-\mathrm{NMR}$ (DMSO$\left.d_{6}, \mathrm{ppm}\right) \delta: 39.66\left(\mathrm{~N}\left(\underline{\mathrm{CH}}_{3}\right)_{2}\right), 111.50,120.82,124.67,125.50$, 129.08, 139.77, 142.15, 151.55 ( $\left.\underline{\mathrm{CH}}_{\text {arom. }}\right), 144.55$ ( $\left.\mathrm{N}=\underline{\mathrm{CH}}\right), 174.47$ $(\underline{C}=S)$. Anal. Calcd. For $\mathrm{C}_{16} \mathrm{H}_{19} \mathrm{~N}_{5} \mathrm{O}_{2} \mathrm{~S}_{2}$ (377.48): C, 50.91; H, 5.07; N, 18.55. Found: C, 50.99; H, 5.12; N, 18.71.

General procedures for the synthesis of 4-(2-(4-

(substituted)benzylidene)hydrazono )-4-oxothiazolidin-3-

yl)benzenesulfonamides $(\mathbf{9 a}, \mathbf{b})$

$10 \mathrm{mmol}$ of monochloroacetic acid and a catalytic amount of anhydrous sodium acetate were added to a solution of compound $\mathbf{8 a}$ or $\mathbf{8 b}(10 \mathrm{mmol})$ in glacial acetic acid $(20 \mathrm{~mL})$. The mixture was refluxed for $24 \mathrm{~h}$ and left to cool then poured into crushed ice. The formed precipitate was filtered off and crystallized from ethanol to give the corresponding 4thiazolidinone derivatives $\mathbf{9 a}, \mathbf{b}$.
4-(2-(4-Chlorobenzylidene)hydrazono )-4-oxothiazolidin-3yl)benzenesulfonamide $(\mathbf{9 a})$

Yield, 53\%; m.p. 288-290 ${ }^{\circ} \mathrm{C}$; IR, $\mathrm{cm}^{-1}$ : 3346, $3261\left(\mathrm{NH}_{2}\right), 3062$ (CH arom.), 2969, 2885 ( $\mathrm{CH}$ aliph.), $1732(\mathrm{C}=\mathrm{O}), 1620(\mathrm{C}=\mathrm{N})$, 1393, $1156\left(\mathrm{SO}_{2}\right) .{ }^{1} \mathrm{H}-\mathrm{NMR}$ (DMSO- $\left.d_{6}, \mathrm{ppm}\right) \delta: 4.13\left(\mathrm{~s}, 2 \mathrm{H}, \mathrm{CH}_{2}\right)$, $7.39\left(\mathrm{~d}, 2 \mathrm{H}, J=8.78 \mathrm{~Hz}, \mathrm{CH}_{\text {arom. }}\right), 7.50\left(\mathrm{~s}, 2 \mathrm{H}, \mathrm{SO}_{2} \mathrm{NH}_{2}\right.$, exchangeable with $\left.\mathrm{D}_{2} \mathrm{O}\right), 7.54\left(\mathrm{~d}, 2 \mathrm{H}, J=8.66 \mathrm{~Hz}, \mathrm{CH}_{\text {arom. }}\right), 7.72$ (d, 2H, J=8.94 Hz, CHarom.), 7.89 (d, 2H, J=8.52 Hz, $\mathrm{CH}_{\text {arom. }}$ ), $8.30(\mathrm{~s}, 1 \mathrm{H}, \mathrm{N}=\mathrm{CH}) .{ }^{13} \mathrm{C}-\mathrm{NMR}$ (DMSO- $\left.d_{6}, \mathrm{ppm}\right) \delta: 32.50\left(\underline{\mathrm{CH}}_{2}\right)$, $126.53,128.84,129.07,130.00,132.87,135.39,137.69,144.13$ $\left(\underline{\mathrm{CH}}_{\text {arom. }}\right), 156.96(\mathrm{~N}=\underline{\mathrm{C}} \mathrm{H}), 165.49(\mathrm{~N}-\underline{\mathrm{C}}=\mathrm{N}), 171.79(\underline{\mathrm{C}}=\mathrm{O})$. Anal. Calcd. For $\mathrm{C}_{16} \mathrm{H}_{13} \mathrm{ClN}_{4} \mathrm{O}_{3} \mathrm{~S}_{2}$ (408.88): C, 47.00; H, 3.20; N, 13.70. Found: C, 47.08; H, 3.22; N, 13.83 .

4-(2-(4-(Dimethylamino)benzylidene)hydrazono)-4-oxothiazolidin3-yl)benzenesulfonamide (9b)

Yield, 46\%; m.p. $218-220{ }^{\circ} \mathrm{C}$; IR, $\mathrm{cm}^{-1}$ : 3317, 3263 $\left(\mathrm{NH}_{2}\right), 3050$ (CH arom.), 2920, 2895 ( $\mathrm{CH}$ aliph.), $1697(\mathrm{C}=\mathrm{O})$, $1596(\mathrm{C}=\mathrm{N}), 1370,1162\left(\mathrm{SO}_{2}\right) .{ }^{1} \mathrm{H}-\mathrm{NMR}\left(\mathrm{DMSO}-d_{6}, \mathrm{ppm}\right) \delta: 2.97$ $\left(\mathrm{s}, 6 \mathrm{H}, \mathrm{N}\left(\mathrm{CH}_{3}\right)_{2}\right), 4.09$ (s, 2H, $\left.\mathrm{CH}_{2}\right), 7.21$ (d, 2H, J=8.63 Hz, $\mathrm{CH}_{\text {arom. }}$ ), 7.50 (s, 2H, $\left.\mathrm{SO}_{2} \mathrm{NH}_{2}\right), 7.56\left(\mathrm{~d}, 2 \mathrm{H}, J=8.71 \mathrm{~Hz}, \mathrm{CH}_{\text {arom. }}\right.$ ), 7.79 (d, 2H, J= $\left.8.99 \mathrm{~Hz}, \mathrm{CH}_{\text {arom. }}\right), 7.94$ (d, 2H, J=9.21 Hz, $\mathrm{CH}_{\text {arom. }}$ ), 8.15 (s, $\left.1 \mathrm{H}, \mathrm{N}=\mathrm{CH}\right) .{ }^{13} \mathrm{C}-\mathrm{NMR}$ (DMSO- $\left.d_{6}, \mathrm{ppm}\right) \delta: 30.57$ $\left(\underline{\mathrm{CH}}_{2}\right), 39.92\left(\mathrm{~N}\left(\underline{\mathrm{CH}}_{3}\right)_{2}\right), 110.96,112.96,121.17,126.39,128.89$, 134.08, 136.75, $151.26\left(\underline{\mathrm{CH}}_{\text {arom. }}\right), 144.09(\mathrm{~N}=\underline{\mathrm{CH}}), 165.80(\mathrm{~N}-$ $\underline{\mathrm{C}}=\mathrm{N}), 174.79(\underline{\mathrm{C}}=\mathrm{O})$. Anal. Calcd. For $\mathrm{C}_{18} \mathrm{H}_{19} \mathrm{~N}_{5} \mathrm{O}_{3} \mathrm{~S}_{2}$ (417.51): $\mathrm{C}$, 51.78; H, 4.59; N, 16.77. Found: C, 51.89; H, 4.62; N, 16.89.

General procedures for the synthesis of ethyl 2-(4(substituted)benzylidene)hydrazono) -4-oxo-3-(4sulfamoylphenyl)thiazolidine-5-carboxylates $(\mathbf{1 0 a}, \mathbf{b})$

$10 \mathrm{mmol}$ of diethylbromomalonate and a catalytic amount of anhydrous sodium acetate were added to a solution of compound $\mathbf{8 a}$ or $\mathbf{8 b}(10 \mathrm{mmol})$ in glacial acetic acid $(20 \mathrm{~mL})$. The mixture was refluxed for $24 \mathrm{~h}$ and left to cool then poured into crushed ice. The formed precipitate was filtered off and crystallized from ethanol to give the corresponding 1,3-thiazolidin4-one derivatives 10a,b.

\section{Ethyl 2-(4-chlorobenzylidene)hydrazono)-4-oxo-3-(4- sulfamoylphenyl)thiazolidine-5-carboxylate (10a)}

Yield, 48\%; m.p. 159-161 ${ }^{\circ} \mathrm{C}$; IR, $\mathrm{cm}^{-1}: 3359,3265$ $\left(\mathrm{NH}_{2}\right), 3092$ (CH arom.), 2980, 2890 (CH aliph.), 1739, 1619 $(2 \mathrm{C}=\mathrm{O}), 1580(\mathrm{C}=\mathrm{N}), 1380,1162\left(\mathrm{SO}_{2}\right) .{ }^{1} \mathrm{H}-\mathrm{NMR}$ (DMSO- $d_{6}$, ppm) $\delta: 1.23\left(\mathrm{t}, 3 \mathrm{H}, J=7.22 \mathrm{~Hz}, \mathrm{CH}_{3}\right), 4.21$ (q, $2 \mathrm{H}, J=7.16 \mathrm{~Hz}$, $\mathrm{CH}_{2}$ ), 4.33 (s, 1H, CH), 7.64 (d, 2H, J=8.71 Hz, $\left.\mathrm{CH}_{\text {arom.) }}\right) 7.66$ (s, $2 \mathrm{H}, \mathrm{SO}_{2} \mathrm{NH}_{2}$, exchangeable with $\left.\mathrm{D}_{2} \mathrm{O}\right), 7.81(\mathrm{~d}, 2 \mathrm{H}, J=8.69 \mathrm{~Hz}$, $\mathrm{CH}_{\text {arom. }}$ ), 7.97 (d, 2H, J= $8.98 \mathrm{~Hz}, \mathrm{CH}_{\text {arom. }}$ ), 8.07 (d, 2H, J= 8.95 $\mathrm{Hz}, \mathrm{CH}_{\text {arom. }}$ ), 8.50 (s, $\left.1 \mathrm{H}, \mathrm{N}=\mathrm{CH}\right) .{ }^{13} \mathrm{C}-\mathrm{NMR}$ (DMSO- $\left.d_{6}, \mathrm{ppm}\right) \delta$ : $13.56\left(\mathrm{CH}_{3}\right), 25.46(\mathrm{HC}-\mathrm{C}=\mathrm{O}), 62.01\left(\mathrm{CH}_{2}\right), 126.58,128.89$, $129.12,130.12,132.93,135.45,137.73,144.18\left(\underline{\mathrm{CH}}_{\text {arom. }}\right), 148.03$ $(\mathrm{N}=\underline{\mathrm{C}} \mathrm{H}), 155.21(\mathrm{~N}-\underline{\mathrm{C}}=\mathrm{N}), 164.21\left(\underline{\mathrm{COOCH}_{2}} \mathrm{CH}_{3}\right), 171.89(\underline{\mathrm{C}}=\mathrm{O})$. Anal. Calcd. For $\mathrm{C}_{19} \mathrm{H}_{17} \mathrm{ClN}_{4} \mathrm{O}_{5} \mathrm{~S}_{2}$ (480.95): C, 47.45; H, 3.56; N, 11.65. Found: C, 47.59; H, 3.60; N, 11.79. 
Ethyl 2-(4-(dimethylamino)benzylidene)hydrazono)-4-oxo-3-(4sulfamoylphenyl)-thiazolidine-5-carboxylate $(\mathbf{1 0 b})$

Yield, 40\%; m.p. $180-182{ }^{\circ} \mathrm{C}$; IR, $\mathrm{cm}^{-1}$ : 3352, 3260 $\left(\mathrm{NH}_{2}\right), 3075$ (CH arom.), 2980, 2891 ( $\mathrm{CH}$ aliph.), 1725, 1612 $(2 \mathrm{C}=\mathrm{O}), 1592(\mathrm{C}=\mathrm{N}), 1368,1196\left(\mathrm{SO}_{2}\right) .{ }^{1} \mathrm{H}-\mathrm{NMR}$ (DMSO-d $d_{6}$, ppm) $\delta$ : $1.18\left(\mathrm{t}, 3 \mathrm{H}, J=7.51 \mathrm{~Hz}, \mathrm{CH}_{3}\right), 2.86\left(\mathrm{~s}, 6 \mathrm{H}, \mathrm{N}\left(\mathrm{CH}_{3}\right)_{2}\right), 4.11$ (q, 2H, J= $\left.7.49 \mathrm{~Hz}, \mathrm{CH}_{2}\right), 4.29$ (s, 1H, CH), 7.07 (d, 2H, J=8.80 $\mathrm{Hz}, \mathrm{CH}_{\text {arom. }}$ ), 7.31 (s, 2H, $\left.\mathrm{SO}_{2} \mathrm{NH}_{2}\right), 7.53$ (d, $2 \mathrm{H}, J=8.90 \mathrm{~Hz}$, $\mathrm{CH}_{\text {arom. }}$ ), 7.62 (d, 2H, J=9.10 Hz, $\mathrm{CH}_{\text {arom. }}$ ), 7.93 (d, 2H, J=8.68 $\mathrm{Hz}, \mathrm{CH}_{\text {arom. }}$ ), 8.18 (s, $\left.1 \mathrm{H}, \mathrm{N}=\mathrm{CH}\right) .{ }^{13} \mathrm{C}-\mathrm{NMR}$ (DMSO- $\left.d_{6}, \mathrm{ppm}\right) \delta$ : $13.93\left(\underline{\mathrm{CH}}_{3}\right), 29.90\left(\mathrm{~N}\left(\underline{\mathrm{CH}}_{3}\right)_{2}\right), 39.96(\mathrm{HC}-\mathrm{C}=\mathrm{O}), 60.71\left(\underline{\mathrm{CH}}_{2}\right)$, $106.88,107.70,110.01,125.87,127.44,129.49,132.08,148.14$ $\left(\underline{\mathrm{C}} \mathrm{H}_{\text {arom }}\right), 145.85(\mathrm{~N}=\underline{\mathrm{CH}}), 188.66\left(\underline{\mathrm{COOCH}}_{2} \mathrm{CH}_{3}\right), 189.20(\underline{\mathrm{C}}=\mathrm{O})$. Anal. Calcd. For $\mathrm{C}_{21} \mathrm{H}_{23} \mathrm{~N}_{5} \mathrm{O}_{5} \mathrm{~S}_{2}$ (489.57): C, 51.52; H, 4.74; N, 14.31. Found: C, 51.63; H, 4.79; N, 14.42.

General procedures for the synthesis of 2-(2-(4-

(substituted)benzylidene)hydrazono)- 4-oxo-3-(4-

sulfamoylphenyl)thiazolidin-5-yl)acetic acids $(\mathbf{1 1 a}, \mathbf{b})$

$10 \mathrm{mmol}$ of maleic anhydride was added to a solution of compound $\mathbf{8 a}$ or $\mathbf{8 b}(10 \mathrm{mmol})$ in glacial acetic acid $(20 \mathrm{~mL})$. The mixture was refluxed for $24 \mathrm{~h}$ and left to cool then poured into crushed ice. The formed precipitate was filtered off and crystallized from ethanol to give the corresponding 1,3-thiazolidin4-one derivatives 11a,b.

\section{2-(-2-(4-Chlorobenzylidene) hydrazono)-4-oxo-3-(4-}

sulfamoylphenyl)thiazolidin-5-yl)acetic acid (11a)

Yield, 39\%; m.p. 229-231 ${ }^{\circ} \mathrm{C}$; IR, cm ${ }^{-1}$ : 3353, 3256 $\left(\mathrm{NH}_{2}\right), 3111(\mathrm{OH}), 3061$ ( $\mathrm{CH}$ arom.), 2933, 2860 ( $\mathrm{CH}$ aliph.), 1705, $1699(2 \mathrm{C}=\mathrm{O}), 1617(\mathrm{C}=\mathrm{N}), 1385,1160\left(\mathrm{SO}_{2}\right) .{ }^{1} \mathrm{H}-\mathrm{NMR}$ $\left(\mathrm{DMSO}-d_{6}, \mathrm{ppm}\right) \delta: 3.10\left(\mathrm{~d}, 2 \mathrm{H}, J=6.50 \mathrm{~Hz}, \mathrm{CH}_{2}\right), 4.58(\mathrm{t}, 1 \mathrm{H}, J=$ $6.87 \mathrm{~Hz}, \mathrm{CH}), 7.45$ (d, 2H, J= $8.88 \mathrm{~Hz}, \mathrm{CH}_{\text {arom. }}$ ), 7.57 (s, 2H, $\mathrm{SO}_{2} \mathrm{NH}_{2}$, exchangeable with $\left.\mathrm{D}_{2} \mathrm{O}\right), 7.61(\mathrm{~d}, 2 \mathrm{H}, J=8.92 \mathrm{~Hz}$, $\mathrm{CH}_{\text {arom. }}$ ), 7.76 (d, 2H, J=8.51 Hz, $\mathrm{CH}_{\text {arom. }}$ ), 7.98 (d, 2H, J=8.59 $\left.\mathrm{Hz}, \mathrm{CH}_{\text {arom. }}\right), 8.36(\mathrm{~s}, 1 \mathrm{H}, \mathrm{N}=\mathrm{CH}), 10.86(\mathrm{~s}, 1 \mathrm{H}, \mathrm{OH}) .{ }^{13} \mathrm{C}-\mathrm{NMR}$ $\left(\mathrm{DMSO}-d_{6}, \mathrm{ppm}\right) \delta: 21.03\left(\underline{\mathrm{CH}}_{2}\right), 42.50(\underline{\mathrm{CH}}), 126.43,128.96$, $129.32,130.00,132.89,135.35,137.82,144.13$ ( $\left.\underline{\mathrm{CH}}_{\text {arom. }}\right), 156.83$ $(\mathrm{N}=\underline{\mathrm{C}} \mathrm{H}), 171.97(\mathrm{~N}-\underline{\mathrm{C}}=\mathrm{N}), 173.65(\underline{\mathrm{C}}=\mathrm{O}), 173.90(\underline{\mathrm{C}}=\mathrm{O})$. Anal. Calcd. For $\mathrm{C}_{18} \mathrm{H}_{15} \mathrm{ClN}_{4} \mathrm{O}_{5} \mathrm{~S}_{2}$ (466.92): C, 46.30; H, 3.24; N, 12.00 . Found: C, 46.42; H, 3.26; N, 12.14 .

\section{2-(2-(4-(Dimethylamino)benzylidene)hydrazono)-4-oxo-3-(4- sulfamoylphenyl)thiazolidin-5-yl)acetic acid (11b)}

Yield, 32\%; m.p. 159-161 ${ }^{\circ} \mathrm{C}$; IR, $\mathrm{cm}^{-1}$ : 3362, 3226 $\left(\mathrm{NH}_{2}\right), 3120(\mathrm{OH}), 3052$ ( $\mathrm{CH}$ arom.), 2914, 2865 ( $\mathrm{CH}$ aliph.), 1709, $1695(2 \mathrm{C}=\mathrm{O}), 1593(\mathrm{C}=\mathrm{N}), 1371,1154\left(\mathrm{SO}_{2}\right) .{ }^{1} \mathrm{H}-\mathrm{NMR}$ (DMSO- $\left.d_{6}, \mathrm{ppm}\right) \delta: 2.96\left(\mathrm{~s}, 6 \mathrm{H}, \mathrm{N}\left(\mathrm{CH}_{3}\right)_{2}\right), 3.11(\mathrm{~d}, 2 \mathrm{H}, J=6.59$ $\left.\mathrm{Hz}, \mathrm{CH}_{2}\right), 4.55$ (t, $\left.1 \mathrm{H}, J=6.88 \mathrm{~Hz}, \mathrm{CH}\right), 6.72(\mathrm{~d}, 2 \mathrm{H}, J=8.61 \mathrm{~Hz}$, $\mathrm{CH}_{\text {arom. }}$ ), 7.52 (s, 2H, $\left.\mathrm{SO}_{2} \mathrm{NH}_{2}\right), 7.56\left(\mathrm{~d}, 2 \mathrm{H}, J=8.99 \mathrm{~Hz}, \mathrm{CH}_{\text {arom. }}\right.$ ), $7.74\left(\mathrm{~d}, 2 \mathrm{H}, J=9.01 \mathrm{~Hz}, \mathrm{CH}_{\text {arom. }}\right), 7.96(\mathrm{~d}, 2 \mathrm{H}, J=8.70 \mathrm{~Hz}$, $\left.\mathrm{CH}_{\text {arom. }}\right), 8.15(\mathrm{~s}, 1 \mathrm{H}, \mathrm{N}=\mathrm{CH}), 10.75(\mathrm{~s}, 1 \mathrm{H}, \mathrm{OH}) .{ }^{13} \mathrm{C}-\mathrm{NMR}$ (DMSO-d $\left.d_{6}, \mathrm{ppm}\right) \delta: 36.74\left(\underline{\mathrm{CH}}_{2}\right), 39.76\left(\mathrm{~N}\left(\underline{\mathrm{CH}}_{3}\right)_{2}\right), 42.45(\underline{\mathrm{CH}})$, $111.53,121.08,126.41,128.80,137.90,143.91,151.94161 .04$
$\left(\underline{\mathrm{CH}}_{\text {arom. }}\right), 158.14(\mathrm{~N}=\underline{\mathrm{CH}}), 171.65(\mathrm{~N}-\underline{\mathrm{C}}=\mathrm{N}), 173.34(\underline{\mathrm{C}}=\mathrm{O}), 173.86$ $(\underline{\mathrm{C}}=\mathrm{O})$. Anal. Calcd. For $\mathrm{C}_{20} \mathrm{H}_{21} \mathrm{~N}_{5} \mathrm{O}_{5} \mathrm{~S}_{2}$ (475.54): $\mathrm{C}, 50.51 ; \mathrm{H}$, 4.45; N, 14.73. Found: C, 50.63; H, 4.49; N, 14.86 .

\section{X-ray crystallography}

Suitable crystals for X-ray single crystal diffraction were selected, coated in perfluoropolyether oil, and mounted on MiTeGen sample holders. Diffraction data of the sample were collected on a Nonius Kappa three circle diffractometer utilizing mirror monochromated MoK $\alpha$ radiation $(\lambda=0.71073 \AA)$ from a rotating anode tube run at $50 \mathrm{~V}$ and $30 \mathrm{~mA}$. The diffractometer is equipped with a Bruker ApexII area detector and an open flow $\mathrm{N}_{2}$ Cryoflex II (Bruker) device. Measurements were performed at 100 K. For data reduction, the Bruker Apex2 software suite (Bruker AXS), was used. Using Olex2 (Dolomanov et al., 2009), the structure was solved with the ShelXS-97 (Sheldrick, 2008)structure solution program using direct methods solution method. The model was refined with XL (Sheldrick, 2008)using Least Squares minimization. All non-hydrogen atom positions were located from the Fourier maps and refined anisotropically. Hydrogen atom positions were calculated using a riding model in geometric positions and refined isotropically.

Cambridge Structural Database (CSD) number: CCDC 1004668.

Crystal Data: $\mathrm{C}_{10} \mathrm{H}_{11} \mathrm{~N}_{3} \mathrm{O}_{3} \mathrm{~S}_{2}, \mathrm{M}_{\mathrm{r}}=285.34$, triclinic, $\mathrm{P}-1$, $\mathrm{a}=$ 9.8121(4) $\AA, b=10.2076(5) \AA, c=24.6210(10) \AA, \alpha=83.992(2)^{\circ}$, $\beta=82.035(2)^{\circ}, \gamma=77.674(2)^{\circ}, \mathrm{V}=2378.71(18) \AA^{3}, \mathrm{~T}=100 \mathrm{~K}$, $\mathrm{Z}=8, \mathrm{Z}^{\prime}=4, \mu\left(\mathrm{MoK}_{\alpha}\right)=0.451,21120$ reflections measured, 9859 unique $\left(\mathrm{R}_{\text {int }}=0.0337\right)$ which were used in all calculations. The final $\mathrm{wR}_{2}$ was 0.2419 (all data) and $\mathrm{R}_{1}$ was $0.0747(I \geq 2 \sigma(I))$.

\section{Antibacterial activity}

Pure compounds were dissolved in sufficient volume of dimethylsulfoxide (DMSO) to make a final concentration of 20 mM. Bacterial strains (S. aureus NCTC 8325, S. aureus HG001, $S$. aureus MA12, S. aureus RN1, S. aureus Xen29, S. epidermidis RP62A, S. epidermidis 195, S. epidermidis 047, E. faecalis JH212, E.faecium 6413, E.coli 536, P. aeruginosa, Y. pestis KUMA, and $Y$. pseudotuberculosis 252 01A) were cultivated overnight at $37^{\circ} \mathrm{C}$ $\left(30^{\circ} \mathrm{C}\right.$ for Yersinia) in Luria-Bertani medium (per liter: $5 \mathrm{~g} \mathrm{NaCl}, 5$ $\mathrm{g}$ yeast extract, $10 \mathrm{~g}$ tryptone) in a shaking incubator.

On the next day, the overnight culture was diluted 1:100 in Müller-Hinton broth (23 g per Liter) and again incubated until the cells reached the exponential growth phase. Approximately, $1 \times 10^{5}$ cells $/ \mathrm{mL}$ were incubated with various concentrations of the compounds $(40,20,10,5,2.5,1.25,0.625$, and $0.3125 \mu \mathrm{M})$ at $37^{\circ} \mathrm{C}$ for $18 \mathrm{~h}\left(30^{\circ} \mathrm{C}\right.$ for $48 \mathrm{~h}$ for Yersinia $)$ to make a final volume of $200 \mu \mathrm{L}$ in a 96-well plate. The final concentration of DMSO was $0.8 \%$ in each well.

After incubation, the optical density of the cultures was determined at $550 \mathrm{~nm}$ wavelength using an ELISA microplate reader (MutlisKan Ascent, Thermo Fisher Scientific) with respect to the control without bacteria. The lowest concentration of a tested compound, where no bacterial growth is detectable, was 
determined as minimum inhibitory concentration (MIC). From substances whose MIC is less than $20 \mu \mathrm{M}$, the overnight cultures from the wells where no bacterial growth was detected were plated on LB agar plates and incubated again overnight. The compound concentration, at which no growth of the bacteria was detectable, was determined as the minimum bactericidal concentration (MBC).

\section{Inhibition of biofilm formation}

Quantitative biofilm of $S$. epidermidis RP62A (ATCC 32984) measurement was done in a microtiter assay. Bacteria were grown overnight in Trypticase Soy Broth / $0.25 \%$ glucose (Becton Dickinson). $100 \mu \mathrm{L}$ of a 1:200 dilution of the overnight culture, with fresh medium, was transferred to 96 -well tissue culture plates (Greiner, Nürtingen, Germany) added to $100 \mu \mathrm{L}$ of a serial dilution of the test compounds in medium. Each compound concentration was measured in five replicates. The DMSO concentration in all wells was $0.8 \%$. Following overnight incubation at $37^{\circ} \mathrm{C}$, the optical density at $550 \mathrm{~nm}\left(\mathrm{OD}_{600}\right)$ of the bacteria was measured and the cultures were poured out. The plates were washed three times with phosphate-buffered saline and the remaining bacteria were fixed by air drying at $60{ }^{\circ} \mathrm{C}$. After staining with $0.4 \%$ crystal violet solution, the optical density of the adherent biofilm was determined at $490 \mathrm{~nm}$. Values $>0.120$ at compound concentrations, with no effect on the bacterial growth in culture, were regarded as biofilm positive.

\section{ACKNOWLEDGEMENTS}

We thank Elena Katzowitsch and Tobias Ölschläger (Institute for Molecular Infection Biology, University of Würzburg) for the antibacterial screening, which was funded by the Deutsche Forschungsgemeinschaft (SFB 630, Z1). We also thank the Institute of Inorganic Chemistry, University of Würzburg, for performing the X-ray measurement.

The authors declare that they have no conflicts of interest.

\section{REFERENCES}

Allen, F.H., Kennard, O., Watson, D.G., Brammer, L., Orpen, A.G., and Taylor, R. Tables of bond lengths determined by X-ray and neutron diffraction. Part 1. Bond lengths in organic compounds. Journal of the Chemical Society, Perkin Transactions, 1987; 2: S1-S19.

Andres, C.J., Bronson, J.J., D'Andrea, S.V., Deshpande, M.S., Falk, P.J., Grant-Young, K.A., Harte, W.E., Ho, H.T., Misco, P.F., Robertson, J.G., et al. 4-Thiazolidinones: novel inhibitors of the bacterial enzyme MurB. Bioorg Med Chem Lett, 2000; 10: 715-717.

Aridoss, G., Amirthaganesan, S., Kim, M.S., Kim, J.T., and Jeong, Y.T. Synthesis, spectral and biological evaluation of some new thiazolidinones and thiazoles based on t-3-alkyl-r-2,c-6-diarylpiperidin-4ones. Eur J Med Chem, 2009; 44: 4199-4210.

Bassetti, M., Merelli, M., Temperoni, C., and Astilean, A. New antibiotics for bad bugs: where are we? Ann Clin Microbiol Antimicrob, 2013; 12: 22

Butler, M.S., Blaskovich, M.A., and Cooper, M.A. Antibiotics in the clinical pipeline in 2013. J Antibiot (Tokyo), 2013;66: 571-591.
Courvalin, P. Vancomycin resistance in gram-positive cocci. Clin Infect Dis, 2006; 42 (Suppl 1), S25-34

Dahl, A., and Bruun, N.E. Enterococcus faecalis infective endocarditis: focus on clinical aspects. Expert Rev Cardiovasc Ther, 2013; 11: $1247-1257$.

de Perio, M.A., Yarnold, P.R., Warren, J., and Noskin, G.A. Risk factors and outcomes associated with non-Enterococcus faecalis, non-Enterococcus faecium enterococcal bacteremia. Infect Control Hosp Epidemiol, 2006; 27: 28-33.

Deshpande, L.M., Fritsche, T.R., Moet, G.J., Biedenbach, D.J., and Jones, R.N. Antimicrobial resistance and molecular epidemiology of vancomycin-resistant enterococci from North America and Europe: a report from the SENTRY antimicrobial surveillance program. Diagn Microbiol Infect Dis, 2007; 58: 163-170.

Dolomanov, O.V., Bourhis, L.J., Gildea, R.J., Howard, J.A.K., and Puschmann, H. OLEX2: a complete structure solution, refinement and analysis program. Journal of Applied Crystallography, 2009; 42: 339-341.

El-Gaby, M.S., El-Hag Ali, G.A., El-Maghraby, A.A., Abd ElRahman, M.T., and Helal, M.H. Synthesis, characterization and in vitro antimicrobial activity of novel 2-thioxo-4-thiazolidinones and 4,4'-bis(2thioxo-4-thiazolidinone-3-yl)diphenylsulfones. Eur J Med Chem, 2009; 44: 4148-4152.

French, G.L. Bactericidal agents in the treatment of MRSA infections--the potential role of daptomycin. The Journal of antimicrobial chemotherapy, 2006; 58: 1107-1117.

Gomes, F., Teixeira, P., and Oliveira, R. Mini-review: Staphylococcus epidermidis as the most frequent cause of nosocomial infections: old and new fighting strategies. Biofouling, 2014; 30: 131-141.

Gopalakrishnan, M., Thanusu, J., and Kanagarajan, V. Design, synthesis, spectral analysis and in vitro microbiological evaluation of 2 phenyl-3-(4,6-diarylpyrimidin-2-yl)thiazolidin-4-ones. J Enzyme Inhib Med Chem, 2009; 24: 1088-1094.

Hoffman, L.R., D'Argenio, D.A., MacCoss, M.J., Zhang, Z., Jones, R.A., and Miller, S.I. Aminoglycoside antibiotics induce bacterial biofilm formation. Nature, 2005; 436: 1171-1175.

Jain, A.K., Vaidya, A., Ravichandran, V., Kashaw, S.K., and Agrawal, R.K. Recent developments and biological activities of thiazolidinone derivatives: a review. Bioorg Med Chem, 2012; 20: 33783395 .

Karatan, E., and Watnick, P. Signals, regulatory networks, and materials that build and break bacterial biofilms. Microbiol Mol Biol Rev, 2009; 73: 310-347.

Kumarasamy, K.K., Toleman, M.A., Walsh, T.R., Bagaria, J., Butt, F., Balakrishnan, R., Chaudhary, U., Doumith, M., Giske, C.G., Irfan, S., et al. Emergence of a new antibiotic resistance mechanism in India, Pakistan, and the UK: a molecular, biological, and epidemiological study. Lancet Infect Dis, 2010; 10: 597-602.

Lewis, K. Platforms for antibiotic discovery. Nat Rev Drug Discov, 2013; 12: 371-387.

Namvar, A.E., Bastarahang, S., Abbasi, N., Ghehi, G.S., Farhadbakhtiarian, S., Arezi, P., Hosseini, M., Baravati, S.Z., Jokar, Z., and Chermahin, S.G. Clinical characteristics of Staphylococcus epidermidis: a systematic review. GMS Hyg Infect Control, 2014; 9: Doc23.

Otto, M. Staphylococcus epidermidis--the 'accidental' pathogen. Nat Rev Microbiol, 2009; 7: 555-567.

Pechous, R.D., Sivaraman, V., Stasulli, N.M., and Goldman, W.E. Pneumonic Plague: The Darker Side of Yersinia pestis. Trends Microbiol, 2015.

Pendleton, J.N., Gorman, S.P., and Gilmore, B.F. Clinical relevance of the ESKAPE pathogens. Expert Rev Anti Infect Ther, 2013; 11: 297-308.

Poyraz, O., Jeankumar, V.U., Saxena, S., Schnell, R., Haraldsson, M., Yogeeswari, P., Sriram, D., and Schneider, G. Structureguided design of novel thiazolidine inhibitors of O-acetyl serine sulfhydrylase from Mycobacterium tuberculosis. J Med Chem, 2013; 56 : 6457-6466. 
Romling, U., and Balsalobre, C. Biofilm infections, their resilience to therapy and innovative treatment strategies. J Intern Med, 2012; 272: 541-561.

Roth, J.S., and Degering, E.F. The Preparation of Sulfanilamide Derivatives Containing a Urea or Thiourea Grouping. Journal of the American Chemical Society, 1945; 67: 126-128.

Sayyed, M., Mokle, S., Bokhare, M., Mankar, A., Surwase, S., Bhusare, S., and Vibhute, Y. Synthesis of some new 2, 3-diaryl-1, 3thiazolidin-4-ones as antibacterial agents. ARKIVOC, 2006; 187-192.

Sheldrick, G.M. A short history of SHELX. Acta Crystallogr A, $2008 ; 64,112-122$.

Sriram, D., Yogeeswari, P., Dhakla, P., Senthilkumar, P. Banerjee, D., and Manjashetty, T.H. 5-Nitrofuran-2-yl derivatives: synthesis and inhibitory activities against growing and dormant mycobacterium species. Bioorg Med Chem Lett, 2009; 19: 1152-1154.

Tong, S.Y., Davis, J.S., Eichenberger, E., Holland, T.L., and Fowler, V.G., Jr. Staphylococcus aureus infections: epidemiology, pathophysiology, clinical manifestations, and management. Clin Microbiol Rev, 2015; 28: 603-661.

Valour, F., Chebib, N., Gillet, Y., Reix, P., Laurent, F., Chidiac, C., and Ferry, T. [Staphylococcus aureus broncho-pulmonary infections]. Rev Pneumol Clin, 2013; 69: 368-382.
Verma, A., and Saraf, S.K. 4-thiazolidinone--a biologically active scaffold. Eur J Med Chem, 2008; 43: 897-905.

Vicini, P., Geronikaki, A., Anastasia, K., Incerti, M., and Zani, F. Synthesis and antimicrobial activity of novel 2-thiazolylimino-5arylidene-4-thiazolidinones. Bioorg Med Chem, 2006; 14: 3859-3864.

Vicini, P., Geronikaki, A., Incerti, M., Zani, F., Dearden, J., and Hewitt, M. 2-Heteroarylimino-5-benzylidene-4-thiazolidinones analogues of 2-thiazolylimino-5-benzylidene-4-thiazolidinones with antimicrobial activity: synthesis and structure-activity relationship. Bioorg Med Chem, 2008; 16: 3714-3724.

\section{How to cite this article:}

El-Hossary EM, Nissan YM, Edkins K, Bruhn H. Synthesis and antibacterial activity of novel 2-(arylimino)thiazolidin-4-one and 2(benzylidenehydrazono)-3-arylthiazolidin-4-one derivatives. J App Pharm Sci, 2016; 6 (05): 007-017. 